\title{
BASE RESEARCH PROGRAM
}

Final Report

(for the period of April 15, 1998, through March 31, 2009)

Prepared for:

AAD Document Control

U.S. Department of Energy

National Energy Technology Laboratory

626 Cochrans Mill Road

PO Box 10940, MS 921-107

Pittsburgh, PA 15236-0940

Cooperative Agreement No. DE-FC26-98FT40320

Project Manager: Richard Read

Prepared by:

Everett A. Sondreal

John G. Hendrikson

Energy \& Environmental Research Center

University of North Dakota

15 North 23rd Street, Stop 9018

Grand Forks, ND 58202-9018 


\section{DISCLAIMER}

This report was prepared as an account of work sponsored by an agency of the United States Government. Neither the United States Government, nor any agency thereof, nor any of their employees, makes any warranty, express or implied, or assumes any legal liability or responsibility for the accuracy, completeness, or usefulness of any information, apparatus, product, or process disclosed, or represents that its use would not infringe privately owned rights. Reference herein to any specific commercial product, process, or service by trade name, trademark, manufacturer, or otherwise does not necessarily constitute or imply its endorsement, recommendation, or favoring by the United States Government or any agency thereof. The views and opinions of authors expressed herein do not necessarily state or reflect those of the United States Government or any agency thereof.

This report is available to the public from the National Technical Information Service, U.S. Department of Commerce, 5285 Port Royal Road, Springfield, VA 22161; phone orders accepted at (703) 487-4650.

\section{EERC DISCLAIMER}

LEGAL NOTICE This research report was prepared by the Energy \& Environmental Research Center (EERC), an agency of the University of North Dakota, as an account of work sponsored by the U.S. Department of Energy. Because of the research nature of the work performed, neither the EERC nor any of its employees makes any warranty, express or implied, or assumes any legal liability or responsibility for the accuracy, completeness, or usefulness of any information, apparatus, product, or process disclosed or represents that its use would not infringe privately owned rights. Reference herein to any specific commercial product, process, or service by trade name, trademark, manufacturer, or otherwise does not necessarily constitute or imply its endorsement or recommendation by the EERC. 


\title{
BASE RESEARCH PROGRAM
}

\begin{abstract}
In June 2009, the Energy \& Environmental Research Center (EERC) completed 11 years of research under the U.S. Department of Energy (DOE) Base Cooperative Agreement No. DEFC26-98FT40320 funded through the Office of Fossil Energy (OFE) and administered at the National Energy Technology Laboratory (NETL). A wide range of diverse research activities were performed under annual program plans approved by NETL in seven major task areas: 1) resource characterization and waste management, 2) air quality assessment and control, 3) advanced power systems, 4) advanced fuel forms, 5) value-added coproducts, 6) advanced materials, and 7) strategic studies. This report summarizes results of the 67 research subtasks and an additional 50 strategic studies. Selected highlights in the executive summary illustrate the contribution of the research to the energy industry in areas not adequately addressed by the private sector alone. During the period of performance of the agreement, concerns have mounted over the impact of carbon emissions on climate change, and new programs have been initiated by DOE to ensure that fossil fuel resources along with renewable resources can continue to supply the nation's transportation fuel and electric power. The agreement has addressed DOE goals for reductions in $\mathrm{CO}_{2}$ emissions through efficiency, capture, and sequestration while expanding the supply and use of domestic energy resources for energy security. It has further contributed to goals for near-zero emissions from highly efficient coal-fired power plants; environmental control capabilities for $\mathrm{SO}_{2}, \mathrm{NO}_{\mathrm{x}}$, fine respirable particulate $\left(\mathrm{PM}_{2.5}\right)$, and mercury; alternative transportation fuels including liquid synfuels and hydrogen; and synergistic integration of fossil and renewable resources (e.g., wind-, biomass-, and coal-based electrical generation).
\end{abstract}




\section{TABLE OF CONTENTS}

EXECUTIVE SUMMARY

INTRODUCTION

TASK 1.0 - RESOURCE CHARACTERIZATION AND WASTE MANAGEMENT ................ 4

Subtask 1.1 - Removal of Organic Pollutants from Subcritical Water with

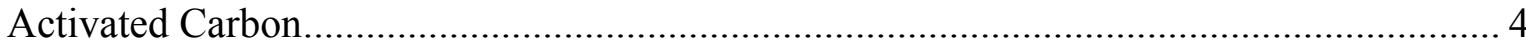

Subtask 1.2 - Mercury Stability in the Environment ....................................................... 4

Subtask 1.3 - Real-Time In Situ Detection of Organic Contaminants by Laser-

Induced Fluorescence System ....................................................................................... 5

Subtask 1.4 - Gas Methane Hydrates for Small Power Systems ......................................... 5

Subtask 1.5 - Activated Carbon from Lignite for Water Treatment Application.................. 6

Subtask 1.6 - Enhancing Electrochemical Processes in Subcritical Water ............................. 6

Subtask 1.7 - Electrolytic Membrane Dialysis for Treating Wastewater Streams ............... 7

Subtask 1.8 - Mercury Release from Disturbed Anoxic Soils.............................................. 8

Subtask 1.9 - Subcritical Water Destruction of Organic Pollutants .................................... 8

Subtask 1.10 - Use of Humic Acids to Treat Salt-Impacted Soils ...................................... 9

Subtask 1.11 - Anaerobic Biological Treatment of Produced Water .................................. 10

Subtask 1.12 - Environmental Remediation ..................................................................... 11

Subtask 1.13 - Coalbed Methane Resource Characterization and Waste

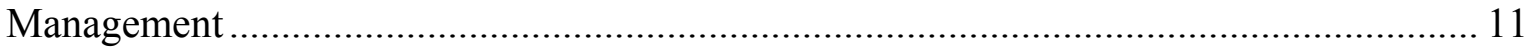

Subtask 1.14 - Mobile Contaminant Recovery System .................................................... 12

Subtask 1.15 - Passive Diffusion Sample Bags Made from Expanded

Polytetrafluoroethylene to Measure VOC Concentrations in Groundwater ........................ 12

Subtask 1.16 - Slow Release Bioremediation Accelerators.............................................. 13

Subtask 1.17 - Measurement of Hydrocarbon Evolution from Coal and Petroleum

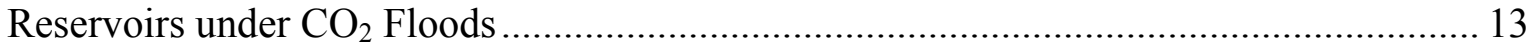

Subtask 1.18 - A Decision Tool for Watershed-Based Effluent Trading ............................ 14

Subtask 1.19 - Characterization of Williston Basin Unconventional Plays ........................ 14

Subtask 1.20 - Development of Methods to Determine the Environmental

Availability of PAHs, PCBs, and Petroleum Hydrocarbons ............................................... 15

Subtask 1.21 - Optimization of Hydrogen Enrichment for Subsurface Delivery................ 15

Subtask 1.22 - Microbial Cycling of $\mathrm{CH}_{4}, \mathrm{CO}_{2}$, and $\mathrm{N}_{2} \mathrm{O}$ in Wetland Environments........ 16

Subtask 1.23 - Mercury Removal from Barite for the Oil Industry …………………….. 17

Subtask 1.24 - Optimization of Cooling Water Resources for Power Generation .............. 18

TASK 2.0 - AIR QUALITY ASSESSMENT AND CONTROL …………………………....... 18

Subtask 2.1 - Value-Added Sorbent Development for Mercury Control ............................ 18

Subtask 2.2 - Fine Particulate ( $\left.\mathrm{PM}_{2.5}\right)$ Characterization and Source Apportionment......... 19

Subtask 2.3 - Carbon Dioxide Sequestering ..................................................................... 20

Subtask 2.4 - Evaluating Short-Term Climate Variability in the Late Holocene of the Northern Great Plains 


\section{TABLE OF CONTENTS (continued)}

Subtask 2.5 - Emissions Control for Diesel Systems .................................................. 21

Subtask 2.6 - Measuring Particulate Levels at High Altitudes Downgradient

from Anthropogenic Sources ..................................................................................... 21

Subtask 2.7 - Examination of Mercury Sources in the Domestic Oil and Gas

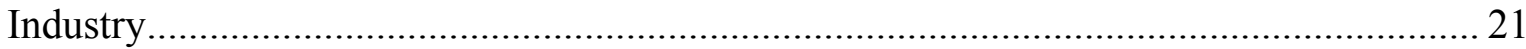

Subtask 2.8 - Control of Trace Elements in Gasification Systems .................................. 22

Subtask 2.9 - Fraction of Organics from Air Particulates with Subcritical Water ............ 22

Subtask 2.10 - Advanced Fine Particulate Characterization Methods .............................. 23

Subtask 2.11 - Staged Electrostatic Precipitator........................................................... 24

Subtask 2.12 - Advanced Characterization and Classification of Particulate Matter......... 25

Subtask 2.13 - Advanced Hybrid Particulate Collector Fundamental Performance ......... 25

TASK 3.0 - ADVANCED POWER SYSTEMS.............................................................. 26

Subtask 3.1 - Low-Temperature Ash Sintering/Strength .......................................... 26

Subtask 3.2 - Characterization and Prediction of Ash Emissivity................................ 26

Subtask 3.3 - High-Temperature Heat Exchanger Testing in a Pilot-Scale Slagging

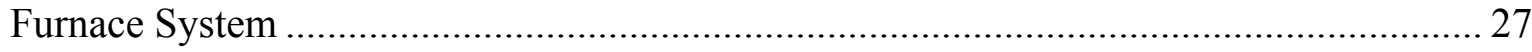

Subtask 3.4 - Impacts of Cofiring Biomass with Fossil Fuels....................................... 28

Subtask 3.5 - Gasification for Distributed Generation ................................................. 28

Subtask 3.6 - Advanced Power System Analysis Tools ................................................. 28

Subtask 3.7 - High-Temperature Heat Exchange Development and Testing ................... 29

Subtask 3.8 - Advanced Power System Studies ............................................................. 30

Subtask 3.9 - High-Speed Computing for Computational Fluid Dynamics Modeling

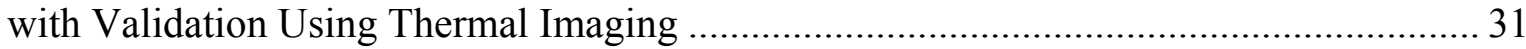

Subtask 3.10 - Power Production from Sour Gas ..................................................... 32

Subtask 3.11 - FutureGen Technologies.................................................................. 32

Subtask 3.12 - Oxygen-Fired CFBC..................................................................... 33

Subtask 3.13 - Enhanced Hydrogen Production from Water-Gas Shift ......................... 34

Subtask 3.14 - Advanced Characterization of Slags and Refractory Bricks Using

Electron Backscatter Diffraction ............................................................................... 34

Subtask 3.15 - Hydrogen Production from High-Temperature Sources ......................... 35

Subtask 3.16 - Low-Btu Oil Field Gas Application to Microturbines.............................. 35

TASK 4.0 - ADVANCED FUEL FORMS ….............................................................. 36

Subtask 4.1 - Conversion of Lignocellulosic Materials to Chemicals and Fuels .............. 36

Subtask 4.2 - Low-Intensity Treatment of Low-Rank Coals, Lignin Waste, and/or Other Biomass to Obtain Liquid Fuel and Products of Added Value..................... 36

Subtask 4.3 - Removal of Sulfur from Diesel Fuel with Subcritical Water ...................... 37

Subtask 4.4 - North Dakota Lignite Fuel Upgrading................................................ 37

Continued ... 


\section{TABLE OF CONTENTS (continued)}

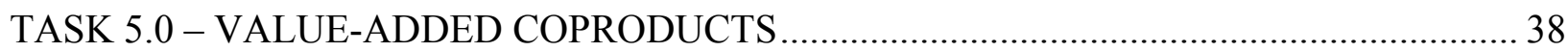

Subtask 5.1 - Effects of Sodium and Calcium Content in Lignite on the

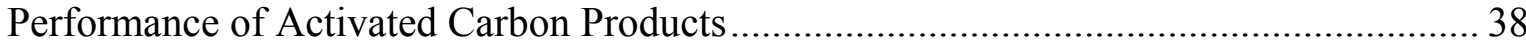

Subtask 5.2 - Development of Carbon Fibers from Low-Rank Coals.............................. 38

Subtask 5.3 - Installation of a Bench-Scale Rotary Kiln Reactor ................................... 39

TASK 6.0 - ADVANCED MATERIALS ...................................................................... 39

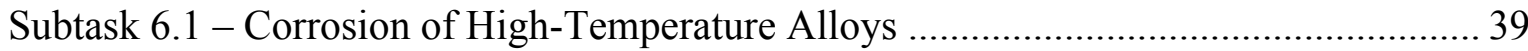

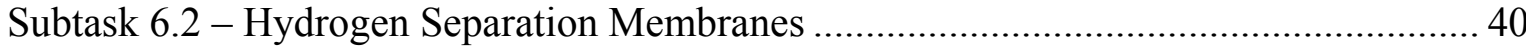

Subtask 6.3 - Silicon Carbide Joining ..................................................................... 40

Subtask 6.4 - Refractory Corrosion in the Metals and Glass Industries ........................... 41

Subtask 6.5 - SiAlON Coatings of Silicon Carbide and Silicon Nitride ........................... 41

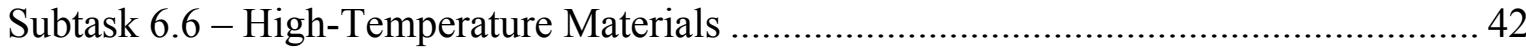

Subtask 6.7 - Corrosion Studies of High-Temperature Alloys...................................... 44

TASK 7.0 - STRATEGIC STUDIES....................................................................... 44

Projects Conducted under Subtask 7.1 ................................................................. 45

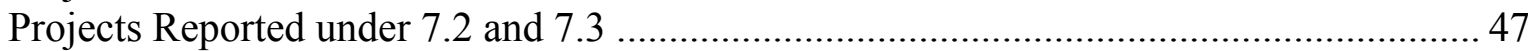

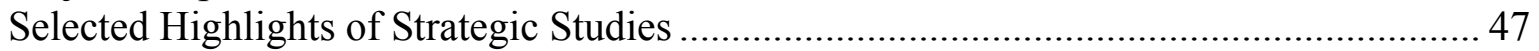

Subtask 7.4 - Powder River Basin Subbituminous Coal-Biomass Cogasification

Testing in a Transport Reactor 


\section{BASE RESEARCH PROGRAM}

\section{EXECUTIVE SUMMARY}

The objective of the Base Cooperative Agreement was to support research on new concepts for highly efficient, nonpolluting energy systems that could compete effectively in meeting the nation's requirements for clean fuels, chemicals, and electricity in the 21 st century. Under Annual Program Plans approved by the National Energy Technology Laboratory (NETL), the content of the research has evolved to match the priority goals of the Office of Fossil Energy, emphasizing energy efficiency, carbon emissions, hydrogen, air quality (e.g., mercury and $\mathrm{PM}_{2.5}$ ), and water resources. Promising concepts have been further developed under a complementary Jointly Sponsored Research Program (JSRP) supporting commercialization by industry. Together, the two agreements have served as the foundation for meeting the original U.S. Department of Energy (DOE) objective for the defederalization and transition of the Energy \& Environmental Research Center (EERC) from the DOE Grand Forks Energy Technology Center (GFETC) with a lead mission in low-rank (western) coal applications to a diversified university-based center that would advance the development of advanced energy technologies not adequately addressed by the private sector alone.

Research performed under the Base Cooperative Agreement has contributed to strategic national goals that have emerged over the period of performance. During this time, concerns have mounted over the impact of carbon emissions on climate change, and new programs have been initiated by DOE to ensure that fossil fuel resources along with renewable resources can continue to supply the nation's transportation fuel and electric power. This agreement has advanced the state of science and technology that defines options for addressing broad national issues in areas that include science-based energy and environmental policy; secure supplies of affordable energy; net reductions in carbon emission; preservation and restoration of the environment; management of water resources; sustainable development; educational foundations; job creation; and international competitiveness. The research has addressed DOE goals for expanded supply and use of domestic energy resources (energy security); near-zero emissions from highly efficient coal-fired power plants; alternative transportation fuels including liquid synfuels and hydrogen; synergistic integration of fossil and renewable resources (e.g., wind-, biomass-, and coal-based electrical generation); environmental control capabilities for $\mathrm{SO}_{2}, \mathrm{NO}_{\mathrm{x}}$, fine respirable particulate $\left(\mathrm{PM}_{2.5}\right)$, and mercury; and reductions in $\mathrm{CO}_{2}$ emissions through efficiency, capture, and sequestration.

Over the life of this agreement, a wide range of research activities were performed under Annual Program Plans approved by NETL in seven major task areas: 1) resource characterization and waste management, 2) air quality assessment and control, 3) advanced power systems, 4) advanced fuel forms, 5) value-added coproducts, 6) advanced materials, and 7) strategic studies. All of these diverse activities are summarized in the body of this report, and detailed reports for individual subtasks can be obtained from the EERC or NETL. Selected highlights in this executive summary were chosen to illustrate the significance of the research to the energy industry. 


\section{Selected Highlights}

- Characterized geological formations for discovery and production of deep gas and oil, including the Bakken Formation, and for sequestration of carbon dioxide (see Subtask 1.19).

- Modeled the water quality impacts of coalbed methane (CBM) production in the Powder River drainage basin, the feasibility of watershed-based water quality credit trading, and the evaluation of $\mathrm{CO}_{2}$ sequestration with CBM production (see Subtasks 1.18 and 1.13).

- Developed methods for remediation of fuel-related soil and water pollution by techniques of extraction, absorption, freezing, and in situ or above-ground biological treatment (see Subtasks 1.1, 1.5, 1.6, 1.7, 1.9-1.12, 1.14, 1.16, 1.21).

- Performed studies on the solubility and biological activity of mercury and organic pollutants in soil, and established criteria for determining whether they are mobile and harmful or sequestered (see Subtasks 1.8 and 1.20).

- Elucidated cyclic climate trends over the past 2000 years showing 150-year wet-dry cycles for the upper Great Plains based on the sedimentary history in land-locked Devils Lake, North Dakota (see Subtasks 2.4 and 7.1).

- Determined absorption properties of supercritical $\mathrm{CO}_{2}$ on core samples of geologic strata from oil fields, including the amounts released after depressurization (see Subtask 1.17).

- Established laboratory verification that algae can be successfully grown by sparging coal combustion flue gas into pond water to reduce $\mathrm{CO}_{2}$ emissions (see Subtask 2.3).

- Performed laboratory studies and field monitoring to quantify the beneficial effects of microbial cycling of $\mathrm{CH}_{4}, \mathrm{CO}_{2}$, and $\mathrm{N}_{2} \mathrm{O}$ in restored wetlands in the Prairie Pothole Region (see Subtask 1.22).

- Identified fundamental mechanisms controlling the capture of mercury emissions from coalfired power plants, focusing on control technologies for low-chlorine western coal and highsulfur eastern bituminous coals, and development of improved sorbents (see Subtask 2.1).

- Evaluated mercury sorbents under reducing conditions for gasification systems (see Subtask 2.8).

- Produced preliminary findings that mercury in coal ash or captured on activated carbon is stable to leaching and offgasing under most environmental conditions (see Subtask 1.2).

- Developed new methods for in-plant and ambient sampling, scanning electron microscopy (SEM) and spectral analysis, and fluid extraction for characterizing air and water pollutants (see Subtasks 1.3 and 1.15). 
- Performed fine particulate matter $\left(\mathrm{PM}_{2.5}\right)$ characterization and source determination by atmospheric sampling, microanalysis, and toxicological assay (see Subtasks 2.2, 2.6, 2.9, 2.10 , and 2.12).

- Validated a staged electrostatic precipitator (ESP) and the ESP-fabric filter (Advanced Hybrid $^{\mathrm{TM}}$ ) for high-efficiency control of fine particulate emissions (see Subtasks 2.5, 2.11, and 2.13).

- Developed a pilot-scale coal-fired, slagging furnace and high-temperature heat exchanger for indirectly fired gas turbine-combined-cycle power generation (see Subtask 3.7).

- Achieved cogasification of biomass and coal in the transport reactor development unit (TRDU) in support of the KBR Transport Gasifier at the Power Systems Development Facility (see Subtask 7.1).

- Developed a suite of analytical methods and predictive models for the Electric Power Research Institute and the power industry to predict fuel quality impacts (see Subtasks 3.1, $3.2,3.4-3.6,3.8$, and 3.9).

- Performed a systems engineering study showing the feasibility of producing liquid transportation fuels and electric power in pulp and paper mills by cogasification of biomass and coal (see Subtask 7.1).

- Demonstrated the use of a coal-liquid $\mathrm{CO}_{2}$ slurry for feeding high-moisture coal to an entrained-flow gasifier (see Subtask 3.11).

- Achieved oxycombustion in an $\mathrm{O}_{2}-\mathrm{H}_{2} \mathrm{O}$ atmosphere in the laboratory and with flue gas recycle in pilot-scale tests; designed studies on retrofitting circulating fluidized-bed combustors to oxygen firing (see Subtasks 3.11 and 3.12).

- Produced design modifications for using microturbines in oil field applications to allow operation on low-Btu gas that is typically flared. Performed field demonstrations on low-Btu and sour gas (see Subtasks 3.10 and 3.16).

- Recovered water from flue gases generated from different fuels and combustion conditions (air versus oxygen) by use of either a condensing heat exchanger or a desiccant system (see Subtask 7.1).

- Performed an engineering study showing that integration of freeze-thaw/evaporation (FTE $\left.{ }^{\circledR}\right)$ into a 475-MW power plant would reclaim cooling tower blowdown and increase output by 4 MW (see Subtask 7.1).

- Performed a systems study showing that large-scale wind power with gas backup can be competitive with new fossil-fueled plants with carbon capture after state and federal wind incentives (see Subtask 7.1). 
- Achieved verification of staged, low-intensity direct coliquefaction of lignite and biomass in support of the development of military jet fuel (JP-8) from nonpetroleum sources (see Subtasks 4.2 and 7.1).

- Developed magnesium alloy hydrides for hydrogen storage (see Subtask 3.11).

- Enhanced hydrogen production in the water-gas shift reaction using $\mathrm{CO}_{2}$ sorbents (see Subtask 3.13).

- Produced new high-temperature materials for advanced power systems, including reactionbonded silicon carbide and coatings made from nanoparticles of yttria and silica (see Subtasks 3.14, 6.3, 6.5, and 6.6).

- Determined the corrosion rates of high-temperature alloys for use in ultrasupercritical boilers firing high-alkali coals and coal-biomass blends (see Subtasks 3.3, 3.14, 6.1, 6.4, and 6.7). 


\section{BASE RESEARCH PROGRAM}

\section{INTRODUCTION}

In June 2009, the Energy \& Environmental Research Center (EERC) completed 11years of research under the U.S. Department of Energy (DOE) Base Cooperative Agreement No. DEFC26-98FT40320 funded through the Office of Fossil Energy (OFE) and administered at the National Energy Technology Laboratory (NETL). The objective of the agreement was to support the performance of advanced research on new concepts for highly efficient, nonpolluting energy systems that could compete effectively in meeting the nation's requirements for clean fuels, chemicals, and electricity in the 21st century. Under Annual Program Plans approved by NETL, the content of the research has evolved to match the priority goals of the Office of Fossil Energy, emphasizing carbon emissions, hydrogen, air quality (e.g., mercury and $\mathrm{PM}_{2.5}$ ), and water resources. Promising concepts have been further developed under a complementary Jointly Sponsored Research Program (JSRP) supporting commercialization by industry, Agreement No. DE-FC26-98FT40321, which is covered in a separate final report. The two Cooperative Agreements (Base and JSRP) were established as a comprehensive model for research, development, demonstration, and commercialization (RDD\&C) partnerships among government, industry, and the applied science and engineering community. Together, they have served as the foundation for meeting the original DOE objective for the defederalization and transition of the EERC from a DOE Energy Technology Center with a lead mission in low-rank (western) coal applications to a diversified university-based center that would advance the development and deployment of advanced energy technologies not adequately addressed by the private sector alone.

Research was performed in seven major task areas: 1) resource characterization and waste management, 2) air quality assessment and control, 3) advanced power systems, 4) advanced fuel forms, 5) value-added coproducts, 6) advanced materials, and 7) strategic studies. Activities in Task 8 addressed financial and topical reporting requirements. The agreement provided flexibility to change the scope and content of the research from year to year with the approval of DOE to respond to national policy goals, program priorities, funding levels, and industry guidance.

This report provides summaries of the 67 research subtasks performed within the first six major task areas, as listed in Table 1. Detailed reports for individual subtasks can be obtained from the EERC or NETL. An additional 50 activities were performed in the seventh area of Strategic Studies to provide technical and policy guidance to senior researchers and managers for planning future research and to perform a limited number of larger studies at the request of NETL. A separate Final Report on Subtask 7.1 has been submitted to NETL and summarizes individual activities in Strategic Studies. Coverage in this report will be limited to an overview of selected highlights. 
Table 1. Research Tasks and Subtasks

\begin{tabular}{|c|c|}
\hline Task & Name \\
\hline 1.0 & Resource Characterization and Waste Management \\
\hline 1.1 & Removal of Organic Pollutants from Subcritical Water with Activated Carbon \\
\hline 1.2 & Mercury Stability in the Environment \\
\hline 1.3 & $\begin{array}{l}\text { Real-Time In Situ Detection of Organic Contaminants by Laser-Induced } \\
\text { Fluorescence System }\end{array}$ \\
\hline 1.4 & Gas Methane Hydrates for Small Power Systems \\
\hline 1.5 & Activated Carbon from Lignite for Water Treatment Application \\
\hline 1.6 & Enhancing Electrochemical Processes in Subcritical Water \\
\hline 1.7 & Electrolytic Membrane Dialysis for Treating Wastewater Streams \\
\hline 1.8 & Mercury Release from Disturbed Anoxic Soils \\
\hline 1.9 & Subcritical Water Destruction of Organic Pollutants \\
\hline 1.10 & Use of Humic Acids to Treat Salt-Impacted Soils \\
\hline 1.11 & Anaerobic Biological Treatment of Produced Water \\
\hline 1.12 & Environmental Remediation \\
\hline 1.13 & Coalbed Methane Resource Characterization and Waste Management \\
\hline 1.14 & Mobile Contaminant Recovery System \\
\hline 1.15 & $\begin{array}{l}\text { Passive Diffusion Sample Bags Made from Expanded Polytetrafluoroethylene to } \\
\text { Measure VOC Concentrations in Groundwater }\end{array}$ \\
\hline 1.16 & Slow Release Bioremediation Accelerators \\
\hline 1.17 & $\begin{array}{l}\text { Measurement of Hydrocarbon Evolution from Coal and Petroleum Reservoirs under } \\
\mathrm{CO}_{2} \text { Floods }\end{array}$ \\
\hline 1.18 & A Decision Tool for Watershed-Based Effluent Trading \\
\hline 1.19 & Characterization of Williston Basin Unconventional Plays \\
\hline 1.20 & $\begin{array}{l}\text { Development of Methods to Determine the Environmental Availability of PAHs, } \\
\text { PCBs, and Petroleum Hydrocarbons }\end{array}$ \\
\hline 1.21 & Optimization of Hydrogen Enrichment for Subsurface Delivery \\
\hline 1.22 & Microbial Cycling of $\mathrm{CH}_{4}, \mathrm{CO}_{2}$, and $\mathrm{N}_{2} \mathrm{O}$ in Wetland Environments \\
\hline 1.23 & Mercury Removal from Barite for the Oil Industry \\
\hline 1.24 & Optimization of Cooling Water Resources for Power Generation \\
\hline 2.0 & Air Quality Assessment and Control \\
\hline 2.1 & Value-Added Sorbent Development for Mercury Control \\
\hline 2.2 & Fine Particulate $\left(\mathrm{PM}_{2.5}\right)$ Characterization and Source Apportionment \\
\hline 2.3 & Carbon Dioxide Sequestering \\
\hline 2.4 & $\begin{array}{l}\text { Evaluating Short-Term Climate Variability in the Late Holocene of the Northern } \\
\text { Great Plains }\end{array}$ \\
\hline 2.5 & Emissions Control for Diesel Systems \\
\hline 2.6 & $\begin{array}{l}\text { Measuring Particulate Levels at High Altitudes Downgradient from Anthropogenic } \\
\text { Sources }\end{array}$ \\
\hline 2.7 & Examination of Mercury Sources in the Domestic Oil and Gas Industry \\
\hline 2.8 & Control of Trace Elements in Gasification Systems \\
\hline 2.9 & Fraction of Organics from Air Particulates with Subcritical Water \\
\hline 2.10 & Advanced Fine Particulate Characterization Methods \\
\hline 2.11 & Staged Electrostatic Precipitator \\
\hline
\end{tabular}




\begin{tabular}{|l|l|}
\hline 2.12 & Advanced Characterization and Classification of Particulate Matter \\
\hline 2.13 & Advanced Hybrid Particulate Collector Fundamental Performance \\
\hline 3.0 & Advanced Power Systems \\
\hline 3.1 & Low-Temperature Ash Sintering/Strength \\
\hline 3.2 & Characterization and Predication of Ash Emissivity \\
\hline 3.3 & High-Temperature Heat Exchanger Testing in a Pilot-Scale Slagging Furnace System \\
\hline 3.4 & Impacts of Cofiring Biomass with Fossil Fuels \\
\hline 3.5 & Gasification for Distributed Generation \\
\hline 3.6 & Advanced Power System Analysis Tools \\
\hline 3.7 & High-Temperature Heat Exchange Development and Testing \\
\hline 3.8 & Advanced Power Systems Studies \\
\hline 3.9 & $\begin{array}{l}\text { High-Speed Computing for Computational Fluid Dynamics Modeling with } \\
\text { Validation Using Thermal Imaging }\end{array}$ \\
\hline 3.10 & Power Production from Sour Gas \\
\hline 3.11 & FutureGen Technologies \\
\hline 3.12 & Oxygen-Fired CFBC \\
\hline 3.13 & Enhanced Hydrogen Production from Water-Gas Shift \\
\hline 3.14 & $\begin{array}{l}\text { Advanced Characterization of Slags and refractory Bricks Using Electron Backscatter } \\
\text { Diffraction }\end{array}$ \\
\hline 3.15 & Hydrogen Production from High-Temperature Sources \\
\hline 3.16 & Low-Btu Oil Field Gas Application to Microturbines \\
\hline $\mathbf{4 . 0}$ & Advanced Fuel Forms \\
\hline 4.1 & Conversion of Lignocellulosic Materials to Chemicals and Fuels \\
\hline 4.2 & $\begin{array}{l}\text { Low-Intensity Treatment of Low-Rank Coals, Lignin Waste, and/or Other Biomass to } \\
\text { Obtain Liquid Fuel and Products of Added Value }\end{array}$ \\
\hline 4.3 & Removal of Sulfur from Diesel Fuel with Subcritical Water \\
\hline 4.4 & North Dakota Lignite Fuel Upgrading \\
\hline $\mathbf{5 . 0}$ & Value-Added Coproducts \\
\hline 5.1 & $\begin{array}{l}\text { Effects of Sodium and Calcium Content in Lignite on the Performance of Activated } \\
\text { Carbon Products }\end{array}$ \\
\hline 5.2 & Development of Carbon Fibers from Low-Rank Coals \\
\hline 5.3 & Installation of a Bench-Scale Rotary Kiln Reactor \\
\hline $\mathbf{6 . 0}$ & Advanced Materials \\
\hline 6.1 & Corrosion of High-Temperature Alloys \\
\hline 6.3 & Hydrogen Separation Membranes \\
\hline 6.4 & Silicon Carbide Joining \\
\hline 6.5 & Sefractory Corrosion in the Metals and Glass Industries \\
\hline 6.7 & High Temperature Materials \\
\hline 7.0 & Corrosion Studies of High-Temperature Alloys \\
\hline 7.4 & $\begin{array}{l}\text { Powder River Basin Subbituminous Coal-Biomass Cogasification Testing in a } \\
\text { Transport Reactor }\end{array}$ \\
\hline
\end{tabular}




\section{TASK 1.0 - RESOURCE CHARACTERIZATION AND WASTE MANAGEMENT}

\section{Subtask 1.1 - Removal of Organic Pollutants from Subcritical Water with Activated Carbon}

At the Energy \& Environmental Research Center (EERC), pollutants including polychlorinated biphenyls (PCBs), pesticides, and polycyclic aromatic hydrocarbons (PAHs) were extracted in subcritical water at ca. $250^{\circ} \mathrm{C}$ and subsequently concentrated by adsorption on activated carbon or by flocculation of humates coextracted from the soil. Adsorption on activated carbon was greater at $200^{\circ}$ than at $25^{\circ} \mathrm{C}$ in the presence of soil humates; the reverse was true for model compounds in clean water. These initial results are opposite to those expected from chromatographic theory, since the solubility of the organics is about 100,000-fold higher in the hot water than in ambient water. The physicochemical mechanism accounting for these results is unknown; however, it is possible that the lower surface tension and lower viscosity of subcritical water (compared to water at ambient conditions) greatly increased the available area of the carbon by orders of magnitude. Also, humates act as surfactants at room temperature, holding pollutants in solution and reducing their adsorption on carbon. While these investigations focused on the cleanup of wastewater generated from subcritical water remediation, the results also apply to cleanup of any wastewater contaminated with nonpolar and moderately polar organics such as wastewaters from coal and petroleum processing.

Hawthorne, S.B.; Lagadec, A. Subtask 1.1 - Removal of Organic Pollutants from Subcritical Water with Activated Carbon; Final Topical Report (Apr 15, 1998 - Apr 30, 1999) for U.S. Department of Energy Cooperative Agreement No. DE-FC26-98FT40320; EERC Publication 99-EERC-08-02; Energy \& Environmental Research Center: Grand Forks, ND, Aug 1999.

\section{Subtask 1.2 - Mercury Stability in the Environment}

A scoping study was performed in advance of the year 2000 decision of the U.S. Environmental Protection Agency (EPA) to regulate mercury from coal-fired plants: 1) to determine from the literature what was known concerning the fate of captured mercury in the environment after it is captured on a solid or in solution and 2) to perform leaching and thermal desorption tests on selected samples of fly ash, scrubber sludge, and mercury sorbents to measure the stability of their contained mercury. Two leaching protocols were performed for 18 hours and 2-4 weeks, respectively, using deionized water. Thermal desorption was measured by heating samples from ambient to $500^{\circ} \mathrm{C}$. In current tests, only minute amounts of mercury of less than $0.1 \%$ of the amount present, measured at near detection limits, were leached from samples of coal fly ash, waste incinerator ash, or flue gas desulfurization samples - which supported the limited findings reported in the literature. Mercury was leached from one activated carbon, at $2.1 \%$ of the loaded mercury, but all other carbons leached less than $0.1 \%$. No measurable thermal desorption occurred below $150^{\circ} \mathrm{C}$, suggesting little potential for devolatilization into the environment for the samples studied. Mercury was desorbed at $220^{\circ} \mathrm{C}$ from fly ash spiked with $\mathrm{HgCl}_{2}$ and at $355^{\circ} \mathrm{C}$ from a sample spiked with $\mathrm{HgO}$. Mercury in offgas has been reported in the literature for other materials, including municipal landfills and sewage sludge. Although preliminary results were generally encouraging, indicating that captured mercury would be stable under most environmental conditions, the limited amount of information available indicated that 
more study was needed, focusing in particular on leachability and offgasing for different mercury sorbents.

Pavlish, J.H. Subtask 1.2 - Mercury Stability in the Environment; Final Report (Apr 15, 1998 June 30, 1999) for U.S. Department of Energy Cooperative Agreement No. DE-FC2698FT40320; EERC Publication 99-EERC-09-03; Energy \& Environmental Research Center: Grand Forks, ND, Sept 1999.

\section{Subtask 1.3 - Real-Time In Situ Detection of Organic Contaminants by Laser- Induced Fluorescence System}

A truck-mounted laser-induced fluorescence (LIF) sensor to detect PAHs in contaminated soils was demonstrated at a well-characterized, active Superfund site, Number 980609804, in St. Louis Park, Minnesota, contaminated with coal tars, creosote, and carcinogenic PAHs. LIF imaging is an optical technique in which the fluorescence of compounds irradiated by a laser is measured. LIF can be used to detect either subsurface petroleum hydrocarbons or uranium and provides a method to rapidly survey a site. LIF measurements made to a depth of $10 \mathrm{ft}$ provided fluorescence intensity profiles that delineated the interface between the 5- to 8-ft-thick uncontaminated fill and the underlying PAH-contaminated materials. Comparison with laboratory soil analysis indicated that the LIF technique was not capable of detailed hydrocarbon speciation, but the LIF results did indicate a high total PAH concentration. The results of the field demonstration showed that the field-deployed LIF method can provide information on hot spots and contaminant plume geometry to guide sampling efforts and placement of monitoring wells. Minimal wastes are generated, and worker exposure to potentially hazardous materials is substantially less than during conventional drilling and sampling activities.

Solc, J.; Sorensen, J.A.; Stepan, D.J. Subtask 1.3 - Real-Time In Situ Detection of Organic Contaminants by Laser-Induced Fluorescence System; Final Topical Report for U.S. Department of Energy Cooperative Agreement No. DE-FC26-98FT40320; EERC Publication 99-EERC-08-07; Energy \& Environmental Research Center: Grand Forks, ND, Aug 1999.

\section{Subtask 1.4 - Gas Methane Hydrates for Small Power Systems}

Methane hydrate deposits worldwide in permafrost regions and on the seafloor off continental margins are estimated to be two orders of magnitude greater than recoverable conventional methane resources, and the carbon associated with these methane hydrates may account for twice that associated with all other fossil fuel resources combined. The original objective of this task was to compile an assessment of methane hydrate deposits in Alaska from available sources and to make a preliminary evaluation of the technical and economic feasibility of producing methane from these deposits for remote power generation. After an extensive literature review and consultation with the U.S. Geological Survey (USGS), the Canadian Geological Survey, and several oil companies, it became evident that the available information on methane hydrates in Alaska was not sufficient to assess their use for energy production. Hence the focus was changed, and an annotated bibliography on gas hydrates was compiled to guide future research. 
Bolles, B.A.; Solc, J. Subtask 1.4 - Gas Methane Hydrates - Research Status, Annotated Bibliography, and Energy Implications; Final Report for U.S. Department of Energy Cooperative Agreement No. DE-FC26-98FT40320; EERC Publication 2000-EERC-09-04; Energy \& Environmental Research Center: Grand Forks, ND, Sept 2000.

\section{Subtask 1.5 - Activated Carbon from Lignite for Water Treatment Application}

Chlorinated by-products formed from humates in surface water during chlorination treatment are required be controlled under new drinking water standards. The humate precursors can be removed in water treatment prior to chlorination using powdered activated carbon. Previous studies had indicated that a commercial carbon prepared from Texas lignite (DARCO HDB) was superior to those prepared from bituminous coals for water treatment. It was hypothesized that North Dakota lignites containing high concentrations of sodium could be used to produce activated carbon having large pores that would provide a higher adsorptive capacity for the large humate molecules, owing to the catalytic effect of the sodium to enlarge pores during the steam activation process. The powdered activated carbon prepared from one highsodium North Dakota lignite in a 100-g batch unit was found to be comparable, and that from a different high-sodium lignite from another mine superior, to the commercially available DARCO HDB carbon. A study of activation conditions showed that steam activation at $750^{\circ} \mathrm{C}$ provided the highest activity with the high-sodium lignite char. An attempt to scale up the carbon production to the $2-\mathrm{kg}$ scale failed to produce the same high activity that was obtained in the 100 -g batch unit, indicating that further work would be required to engineer a continuous process duplicating the conditions of the small batch unit.

Olson, E.S.; Stepan, D.J. Subtask 1.5 - Activated Carbon from Lignite for Water Treatment; Final Report for U.S. Department of Energy Cooperative Agreement No. DE-FC2698FT40320; EERC Publication 00-EERC-07-06; Energy \& Environmental Research Center: Grand Forks, ND, July 2000.

\section{Subtask 1.6 - Enhancing Electrochemical Processes in Subcritical Water}

Many electrochemical processes related to energy production are technically feasible but economically limited. Fundamental problems limiting processes such electrolysis, fuel cells, and electrochemical decomposition of organic wastes include 1) low rates of mass transfer and electrode dynamics, 2) need for high overvoltages, and 3) low aqueous solubilities for many organic pollutants. Studies on the properties of water above its boiling point under enough pressure to maintain the liquid state at subcritical conditions (typically $100^{\circ}$ to $250^{\circ} \mathrm{C}$, but always less than the critical temperature of $374^{\circ} \mathrm{C}$ ) indicate that the dielectric constant drops from 80 to about 20, giving water the solvent properties of organic solvents such as acetonitrile or methanol, both the viscosity and the surface tension of water drop by an order of magnitude, and increased concentrations of $\mathrm{H}^{+}$and $\mathrm{OH}^{-}$by a factor of 20. The important implications of these changes for electrochemical processes are that mass transfer will increase, ionic conductivity should increase because of increased diffusion coefficients, the solubilities of organics (e.g., PCBs) should increase, and hydrolysis (and possibly other reactions) of organics will be enhanced. Although only a very few research papers in the literature describe work in subcritical water, these important implications are supported by past studies showing that the solubilities of hydrophobic 
organic pollutants increase by 4 to 6 orders of magnitude in subcritical water, that the degradation of pesticides and explosives including cycloteramethylene tetranitramine (HMX), cyclotrimethylene trinitramine (RDX), and trinitrotoluene (TNT) and dechlorination of several types of organic pollutants can be accomplished using only pure water in the subcritical state. Initial electrochemical measurements in subcritical water demonstrated that the diffusion coefficient of $\mathrm{Cu}^{2+}$ increases by 100 -fold in subcritical water, thus proving that enhanced mass transfer is achieved. Finally, the electrolysis of water to $\mathrm{H}_{2}$ and $\mathrm{O}_{2}$ in subcritical water was demonstrated (using 50\% KOH with $\mathrm{Ni}$ electrodes), demonstrating the potential for subcritical water to reduce the overpotential required for hydrogen production

In this task, an electrochemical cell was designed, built, and successfully demonstrated to give substantially better performance than presently available. The electrochemical conductivity of subcritical water increased substantially with temperature, e.g., conductivities increased by a factor of 120 when the temperature was increased from $25^{\circ}$ to $250^{\circ} \mathrm{C}$. Cyclic voltammograms obtained with platinum and nickel demonstrated that the voltage required to produce hydrogen and oxygen from water can be dropped by a factor of three in subcritical water compared to the voltages required at ambient temperatures. However, no enhancement in the degradation of 1,2-dichlorobenzene and the polychlorinated biphenyl 3,3',4,4'-tetrachlorobiphenyl was observed with applied potential in subcritical water.

Hawthorne, S.B. Subtask 1.6 - Enhanced Electrochemical Processes in Subcritical Water; Final Report for U.S. Department of Energy Agreement No. DE-FC26-98FT40320; EERC Publication 2000-EERC-07-02; Energy \& Environmental Research Center: Grand Forks, ND, July 2000.

\section{Subtask 1.7 - Electrolytic Membrane Dialysis for Treating Wastewater Streams}

An electrolytic membrane was investigated for separating chloride $\left(\mathrm{Cl}^{-}\right)$and sulfate $\left(\mathrm{SO}_{4}{ }^{2-}\right)$ from a simulated wastewater containing a copper(II) salt to represent heavy metals. Chloride and sulfate ions are of particular interest because their electrical conduction properties in aqueous solution result in the corrosion of metals. Baseline tests involving simple dialysis (electromotive force $[\mathrm{emf}]=0$ ) indicated only slight change in the rate of chloride transfer across the membrane as a result of increasing the basicity from $\mathrm{pH} 7$ to 14 . Increasing the applied emf from 1 to $3 \mathrm{~V}$ increased the transfer of both chloride and sulfate by as much as $24 \%$. Increasing the emf further to $4 \mathrm{~V}$ caused the transfer of ions to drop precipitously. Ion transfer across the test membrane was selective for $\mathrm{Cl}^{-}$, suggesting that the smaller size of the chloride ions was more important that the greater coulombic force exerted on the divalent sulfate ions. A brown scum forming on the surface of the liquid migrated to coat on the surface of the membrane, reducing the membrane porosity and slowing the transfer of ions. Reversing the direction of ion transfer through the membrane improved permeability only slightly. The results of the study verified that anions can be removed from wastewater using an electrolytic membrane and that the removal is selective. The lifetime of the membrane will be determined by surface blinding.

Timpe, R.C. Subtask 1.7 - Electrolytic Membrane Dialysis for Treating Wastewater Streams; Final Report (May 1, 1999 - Mar 31, 2000) for U.S. Department of Energy Cooperative 
agreement No. DE-FC26-98FT40320; EERC Publication 2000-EERC-05-03; Energy \& Environmental Research Center: Grand Forks, ND, April 2000.

\section{Subtask 1.8 - Mercury Release from Disturbed Anoxic Soils}

The secondary release of mercury from contaminated anoxic sediments after disturbance by stirring, mixing, drying, and resaturating was evaluated in reference to implications for treatment of contaminated soils and issues pertaining to risk analysis. Many previously contaminated sites reach a state of geochemical equilibrium in which contaminants are bound to sediments and are immobilized. In some cases, disturbances associated with site cleanup may remobilize contaminants and cause unnecessary environmental damage.

Experiments were carried out by collecting mercury-contaminated anoxic soil samples and related creek water in the field and performing bench-scale tests involving 1) field simulations of the kind of mixing caused by dredging, followed by water sampling to determine the extent of mercury release; 2) laboratory column studies on mercury release; 3) laboratory drying tests to determine mercury volatilization and partitioning; and 4) laboratory mixing tests to determine mercury release by leaching and devolatilization from disturbed, transported, and dried soils. Mercury releases measured for a field-disturbed soil with a mercury concentration greater than $300 \mathrm{mg} / \mathrm{kg}$ were $2.8 \mu \mathrm{g} / \mathrm{L}$ in filtered water samples and $40 \mu \mathrm{g} / \mathrm{L}$ in unfiltered, both of which exceed EPA standards. Mercury release by volatilization, or in sulfide- or oxide-bound forms, was insignificant. Also, mercury release in column tests was negligible for both disturbed and undisturbed soil samples, but there was significant release of particle-bound mercury in unfiltered samples from column tests performed on dried and resaturated soils. Mercury and other metal contaminants appear to be concentrated in an approximately 50-cm-thick layer in anoxic organic soil, where the prevailing anoxic conditions and sulfide bonding result in environmental stability unless the sediment is disturbed.

The stability observed for mercury in undisturbed anoxic soil may represent an opportunity for treating wastewater highly contaminated with mercury and other toxic metals in natural or engineered anoxic ponds (reactors). A better understanding of the controlling factors would be required to design such a treatment method, including the time required to achieve anaerobic conditions, permissible flow rates, mercury/metal/sulfide bonding, and mercury methylation.

Solc, J.; Bolles, B.A. Subtask 1.8 - Mercury Release from Disturbed Anoxic Soils; Final Report (Feb 1, 1999 - July 31, 2001) for U.S. Department of Energy Cooperative Agreement No. DE-FC26-98FT40320; EERC Publication 2001-EERC-07-05; Energy \& Environmental Research Center: Grand Forks, ND, July 2001.

\section{Subtask 1.9 - Subcritical Water Destruction of Organic Pollutants}

The degradation of chlorinated organic compounds in subcritical waster was studied to develop a new approach for environmental cleanup for this class of pollutants. Dechlorination of aliphatic and aromatic organochlorine pollutants including lindane and tetrachloroethane was successfully performed in subcritical water at temperatures as low as $150^{\circ} \mathrm{C}$ and in reaction times as short as 1 hour. Higher temperatures were required to fully dechlorinate aromatic products 
such as chlorobenzenes and polymers (polyvinyl chloride was dechlorinated at $300^{\circ} \mathrm{C}$ ). Although complete destruction of the polymer matrix was not achieved, analysis of the organic products showed no chlorinated organics. In fact, the organic products formed were primarily low molecular weight alkyl benzenes (and related compounds) which could be burned as a liquid fuel or easily introduced into a petroleum processing stream.

Dechlorination of aromatic organochlorines (such as PCBs and pentachlorophenol) appears to occur by hydride/chloride exchange and requires higher temperatures than dehydrohalogenation. Studies on these reactions were complicated by the fact that alloys such as INCONEL caused somewhat faster dechlorination reactions than occur in glass. However, even in glass, dechlorination occurs at temperatures of $300^{\circ} \mathrm{C}$ or higher. The results indicate that metals present in INCONEL are useful in promoting dechlorination reactions of PCBs. Preliminary studies using metal dust as a dechlorination accelerant show that magnesium is a better accelerant than iron, and iron is much better than nickel or copper. Soil components may also accelerate PCB dechlorination under subcritical water conditions.

Hawthorne, S.B. Task 1.9 - Subcritical Water Destruction of Organic Pollutants; Final Topical Report (Apr 1, 2000 - June 30, 2001) for U.S. Department of Energy Cooperative Agreement No. DE-FC26-98FT40320; EERC Publication 2001-EERC-06-03; Energy \& Environmental Research Center: Grand Forks, ND, June 2001.

\section{Subtask 1.10 - Use of Humic Acids to Treat Salt-Impacted Soils}

Production of oil and gas results in the production of large amounts of brine. Spillage and leaks of these brines have resulted in deleterious impacts to soils. Remediation of salt impacts on soils is often performed by leaching. Hydrophobicity of impacted soils and low-permeability soils generally results in poor remediation. The addition of humic acids has the potential to reduce soil hydrophobicity and to bind sodium, reducing plant toxicity and improving the potential for leaching the salts from the soils. The potential remediation of these salt-impacted soils with humic acids was investigated using two soils and four sources of humic acids.

The soils used in this research were from oil production areas in Louisiana and northern Alberta, Canada. The soils were collected at the site by cooperators and shipped to the EERC. The soils were dried, sieved, and characterized with respect to cations, $\mathrm{pH}$, moisture, texture, conductivity, and bulk density. Four sources of humic acids were obtained: three low-rank coals and one peat. The peat was a reed sedge peat, two of the coals were North Dakota lignites (Freedom and Fallkirk), and the remaining coal was a New Mexico lignite. The humic sources were ground and characterized with respect to humic content, cation content, conductivity, moisture, ability to sorb sodium, ability to reduce plant toxicity, and ability to improve leaching in salt-impacted soils. Plant toxicity was determined by measuring seed germination with lettuce seeds. Leachability was determined in minicolumn tests. Sodium sorption was determined using an equilibrium dialysis method.

The results of these tests showed that the New Mexico lignite had the largest amount of humics, followed, in decreasing order, by Freedom lignite, Falkirk lignite, and the peat. Sodium sorption was positively correlated with humic content, with the exception that the peat sorbed 
nearly as much sodium as the New Mexico lignite. Sodium sorption ranged from $<2$ to $>40 \mathrm{mg}$ of sodium per gram of humic material. In general, the results of the leachability tests showed that the leachability of the soils was similar for all humic materials. In some cases, the peat clearly performed better, probably more a function of the improvements in soil permeability.

Seed germination tests showed that only the peat at doses of $2 \%$ and $5 \%$ resulted in any seed germination and that only after a single water flush. Potential increases in soil wettability or decreases in soil hydrophobicity could not be assessed, as the test soils were not significantly hydrophobic.

Gallagher, J.R. Use of Humic Acid to Treat Salt-Impacted Soils (Base 1.10) Final Report for U.S. Department of Energy Cooperative Agreement No. DE-FC26-98FT40320; EERC Publication 2007-EERC 01; Energy \& Environmental Research Center: Grand Forks, ND, June 2001.

\section{Subtask 1.11 - Anaerobic Biological Treatment of Produced Water}

Treatment of produced water from offshore production facilities is a significant challenge because of constraints on equipment size and hydraulic load. Alkanes are readily removed from water using conventional technology, but naphthenic acids are not. Aerobic treatment has been shown to remove naphthenic acids, but acetate and other organics in the produced water overload the capacity of aerobic systems. Anaerobic treatment should readily remove the acetate, and anaerobic systems can handle a high organic load in a small footprint.

A fixed-film anaerobic bioreactor was constructed and adapted to treat simulated produced water using inoculants from a municipal digester and two salt-tolerant methanogenic bacteria. Rapid production of methane gas was observed during start-up when glucose was added. However, when glucose was removed and the major organic component was acetate, little gas was generated. Small amounts of toluene in the produced water $(0.1 \mathrm{~g} / \mathrm{L})$ were removed.

Batch tests were conducted under both aerobic and anaerobic conditions to determine the biodegradability of naphthenic acid using bacteria from either the anaerobic reactor or wetland sediments. The naphthenic acid was isolated from Gulf Coast petroleum. Incubation was 30 days at $30^{\circ} \mathrm{C}$. Results showed that naphthenic acids could be biodegraded under aerobic conditions but not under anaerobic conditions.

Gallagher, J.R. Subtask 1.11 - Anaerobic Biological Treatment of Produced Water; Final Report (Apr 1, 2000 - July 31, 2001) for U.S. Department of Energy Cooperative Agreement No. DE-FC26-98FT40321; EERC Publication 2001-EERC-07-04; Energy \& Environmental Research Center: Grand Forks, ND, July 2001. 


\section{Subtask 1.12 - Environmental Remediation}

Subtask 1.12 consolidated activities on the following topics:

- Activity 1 provided information on selected sorbents for reducing mercury concentrations in contaminated groundwater and soil. Iron was shown to be effective for in situ treatment.

- Activity 2 presented a seminar on state-of-the-art remediation technologies to scientists, engineers, and regulators from the upper Midwest.

- Activity 3 performed laboratory tests to determine mercury release from the manufacture of gypsum wallboard using flue gas desulfurization (FGD) materials. Test results indicated that the amount of mercury released during calcining would be much higher when using a kettle process that heats materials to $\sim 170^{\circ} \mathrm{C}$ for $1-4$ hours than when using a flash calcining process that heats the material to a lower temperature in less than 2 seconds. No detectible mercury would be released in the board-drying process at $55^{\circ}-60^{\circ} \mathrm{C}$.

- Activity 4 evaluated the technical feasibility of using a refrigeration-based modification of the EERC's ambient freeze-thaw/evaporation $\left(\mathrm{FTE}^{\mathbb{B}}\right)$ process to treat offshore produced water. The process successfully recovered usable water from saltwater, but its application for reclaiming produced water from oil production would not be practical because of difficulties in separating the oil and grease.

- Activity 5 continued experiments started under Subtask 1.11. Results indicated that an anaerobic bioreactor can successfully remove benzene, toluene, and xylenes from produced water, but the same bioreactor was unable to remove acetate.

- Activity 6 synthesized polymers containing nitrogen and phosphorus that slowly hydrolyze to supply nutrients for microbial remediation of subsurface contamination.

Sorensen, J.A. Subtask 1.12 - Environmental Remediation; Final Report (Apr 1, 2002 -Mar 31, 2004) for U.S. Department of Energy Cooperative Agreement No. DE-FC26-98FT40320; EERC Publication 2004-EERC-10-01; Energy \& Environmental Research Center: Grand Forks, ND, Oct 2004.

\section{Subtask 1.13 - Coalbed Methane Resource Characterization and Waste Management}

Coalbed methane (CBM) development in the Powder River Basin of northeastern Wyoming and southeastern Montana has raised concern over impacts on stream water quality. In response, the EERC conducted hydrologic modeling to evaluate the potential impacts from CBM development on the Powder and Little Powder Rivers. The historical natural fluctuations of stream volume and water quality within the basins and the absence of data on irrigation withdrawals complicated the study. However, the results indicated significant changes in stream 
volume and water quality from the introduction of CBM produced waters and supported the appropriateness of recently imposed water quality standards.

Based on the nature of North Dakota lignite and the presence of large-volume $\mathrm{CO}_{2}$ producers in the area, there is significant potential for simultaneous sequestration of $\mathrm{CO}_{2}$ and production of CBM. Potentially economic sources of $\mathrm{CO}_{2}$ are available from the state's lignitefired power plants and the Dakota Gasification Company plant currently supplying $\mathrm{CO}_{2}$ for enhanced oil recovery in Saskatchewan. Samples from lignite seams previously identified as possible sources of CBM in southwestern North Dakota were collected and analyzed in order to develop $\mathrm{CO}_{2}$ adsorption isotherms and methane desorption isotherms. An overview of the geological characteristics of the study area that may affect its suitability as a long-term $\mathrm{CO}_{2}$ repository was developed from literature sources.

Williams, K.D.; XiXi, W.; Sorensen, J.A.; Kurz, M.D. Subtask 1.13 - Coalbed Methane Resource Characterization and Waste Management; Final Report for U.S. Department of Energy Cooperative Agreement No. DE-FC26-98FT40320; EERC Publication 2005-EERC08-05; Energy \& Environmental Research Center: Grand Forks, ND, Aug 2005.

\section{Subtask 1.14 - Mobile Contaminant Recovery System}

The mobile contaminant recovery and treatment system was designed and assembled by the EERC in cooperation with Specialty Systems Integrators, Inc. The system recovers toxic gases and liquids from contaminated soil for characterization and remediation. Equipment and instrumentation including a blower, vapor-liquid separator, oil-water separator, air stripper, and programmable controller are installed on a trailer platform. Special features later added to the system included telemetric control and programmable logic and delivery systems for oxygen and nutrients. This system provides capabilities for either feasibility testing to plan large-scale mitigation or emergency remediation requiring more limited contaminant recovery, containment, and control. Results of field testing validated the system.

Solc, J. Subtask 1.14 - Mobile Contaminant Recovery System; Final Report (Feb 12, 2002 Mar 31, 2004) for U.S. Department of Energy Cooperative Agreement No. DE-FC2698FT40320; Energy \& Environmental Research Center: Grand Forks, ND, Aug 2004.

\section{Subtask 1.15 - Passive Diffusion Sample Bags Made from Expanded Polytetrafluoroethylene to Measure VOC Concentrations in Groundwater}

Laboratory tests were performed on passive diffusion bags (PDBs) made from expanded polytetrafluoroethylene (ePTFE) membrane to determine rate diffusion for volatile organic compounds (VOCs) in groundwater. PDB samplers are used to measure concentrations of a variety of VOCs in groundwater at monitoring wells. The samplers are typically constructed of low-density polyethylene (LDPE). In use, the samples are filled with distilled, deionized water and heat-sealed at both ends. The sleeves are placed in monitoring wells and are allowed to equilibrate with the surrounding water for typically 2 weeks, after which the enclosed water is analyzed. Field tests show good correlation between samples obtained with PDB samplers and samples obtained using traditional purge and sample methods, at significant cost savings, and 
without disturbing the well. Results of laboratory tests indicated that equilibration time can be reduced by 1 week using ePTFE membranes in place of LDPE and that similar rates of diffusion for VOCs can be achieved at lower temperatures $\left(2^{\circ}\right.$ to $\left.3^{\circ} \mathrm{C}\right)$ using ePTFE.

Botnen, B.W. Subtask 1.15 - Passive Diffusion Sample Bags Made from Expanded Polytetrafluoroethylene (ePTFE) to Measure VOC Concentrations in Groundwater; Final Report for U.S. Department of Energy Cooperative Agreement No. DE-FC26-98FT40320; EERC Publication 2006-EERC-09-01; Energy \& Environmental Research Center: Grand Forks, ND, July 2006.

\section{Subtask 1.16 - Slow Release Bioremediation Accelerators}

Nutrient-containing polymers were successfully synthesized to have the properties of sticking to soil particles and degrading slowly over time to enhance biodegradation of hydrocarbon contaminants in soil relative to pure phosphorus and nitrogen compounds alone. One polymer synthesized from glycerol, which is a by-product of biodiesel production, was found to offer synergistic benefits when combined with a commercially available oxygenreleasing compound. Opportunities are going forward with potential industrial partners to jointly sponsor field-trial demonstrations of polymers as a step toward commercial application.

Olson, E.S.; Kurz, M.D. Subtask 1.16 - Slow-Release Bioremediation Accelerators; Final Report (Apr 1, 2004 - June 30, 2006) for U.S. Department of Energy Cooperative Agreement No. DE-FC26-98FT40320; EERC Publication 2006-EERC-08-01; Energy \& Environmental Research Center: Grand Forks, ND, Aug 2006.

\section{Subtask 1.17 - Measurement of Hydrocarbon Evolution from Coal and Petroleum Reservoirs under $\mathrm{CO}_{2}$ Floods}

This project built and tested three apparatuses for studying different interactions of carbon dioxide with geologic materials under geologically relevant conditions of temperature (subambient to $250^{\circ} \mathrm{C}$ ) and pressures (ambient to 400 bar). First, an online instrument was constructed by coupling a high-pressure carbon dioxide extraction system with a flame ionization detector that can yield a real-time profile and quantitative measurements of hydrocarbons removed from materials such as coal and petroleum reservoir rock. Parametric testing using this instrument showed that carbon dioxide pressure and temperature have a significant effect on the amounts of oil recovered from reservoir rock. The second instrument was built to measure the excess sorption of carbon dioxide in geologic materials such as coal; tests showed that measurable uptake of carbon dioxide into coal was rapid. The final apparatus was built to expose geologic materials to carbon dioxide for long periods of weeks to months. As many as twenty gram-sized samples can be tested simultaneously, including tests with exposure to geologic brines. Tests on this system demonstrated complete conversion of magnesium silicate to magnesium carbonate in less than 4 weeks with exposure to either clean water or brine, whereas there was no measurable conversion of dry magnesium silicate to magnesium carbonate.

Hawthorne, S.B. Subtask 1.17 - Measurement of Hydrocarbon Evolution from Coal and Petroleum Reservoirs under Carbon Dioxide; Final Report (Apr 1, 2004 - Dec 31, 2006) for 
U.S. Department of Energy Cooperative Agreement No. DE-FC26-98FT40320; EERC Publication 2007-EERC-04-04; Energy \& Environmental Research Center: Grand Forks, ND, Apr 2004.

\section{Subtask 1.18 - A Decision Tool for Watershed-Based Effluent Trading}

The technical and economic feasibility of watershed-based water quality credit trading of CBM produced water was evaluated in the Powder River drainage basin of Wyoming and Montana. Effluent credit trading is a market-based approach that provides improved water quality management at reduced cost throughout an entire watershed while increasing available water resources. Using this approach, industrial, agricultural, and municipal stakeholders can meet water quality permit requirements governing release of produced water into surface waterways by purchasing pollutant reduction credits from other entities located within the same watershed, thus allowing the credit buyer to discharge an untreated volume of water containing the equivalent mass of potential pollutants contained in the credit, subject to safeguards that avoid the creation of localized "hotspots" that exceed water quality standards. Results of this study indicate that treating $75 \%$ of the CBM produced water in the upper Powder River Basin (PRB) would allow the remaining produced water to be directly discharged without adversely impacting water quality. This would reduce the costs of handling produced water in the PRB by $\$ 684$ million and facilitate the development of up to 10,000 new CBM wells with a potential production capacity of 3 Tcf of natural gas.

Kurz, B.A.; Kurz, M.D.; Xixi, W. Subtask 1.18 - A Decision Tool for Watershed-Based Effluent Trading; Final Report for U.S. Department of Energy Cooperative Agreement No. DE-FC2698FT40320; EERC Publication 2007-EERC-02-05; Energy \& Environmental Research Center: Grand Forks, ND, Feb 2007.

\section{Subtask 1.19 - Characterization of Williston Basin Unconventional Plays}

Maintaining future production of oil and gas resources in the United States depends on the development of unconventional reservoirs. Significant oil and gas resources can be discovered through careful analysis and interpretation of existing data, including well logs, historical production data, engineering reports, geophysical data, and formation fluid characteristics. A project was conducted to find previously unidentified resources in the Williston Basin using public data available through the North Dakota Industrial Commission (NDIC) Oil and Gas Division. Geological, operational, and engineering information on deep gas production from the Beaver Lodge Field in northwestern North Dakota was compiled and organized into a general analog for gas production from deep basins. Maps and cross sections on two deep sedimentary rock formations in the Nesson Anticline area of the Williston Basin, the sandstones of the Winnipeg Group, and the Deadwood Formation provide insight with respect to the unconventional production of natural gas from formations of low porosity and depth below $10,000 \mathrm{ft}$. Data were obtained on historic production of natural gas in association with oil production from these formations. Detailed engineering data were also developed on well drilling and completion techniques. The organized data (analog) served as the basis for the development of a framework for a prototype digital petroleum exploration tool. The digital petroleum exploration tool is geographic information system (GIS)-driven and Web-based. The 
conceptual framework of the Web site has been designed to be expandable and may ultimately provide a platform for analogs representing many conventional and unconventional resource opportunities within the Williston Basin.

Fischer, D.W.; Peck, W.D.; Sorensen, J.A.; Smith, S.A. Subtask 1.19 - Characterization of Williston Basin Unconventional Plays; Final Report (Apr 1, 2006 - Mar 31, 2007) for U.S. Department of Energy Cooperative Agreement No. DE-FC26-98FT40320; EERC Publication 2007-EERC-04-09; Energy \& Environmental Research Center: Grand Forks, ND, April 2007.

\section{Subtask 1.20 - Development of Methods to Determine the Environmental Availability of PAHs, PCBs, and Petroleum Hydrocarbons}

Current regulatory practices are based on the assumption that $100 \%$ of an organic pollutant on soil or sediment is available to environmental processes such as water transport and uptake by organisms. However, recent evidence demonstrates that hydrophobic organic pollutants become less available to the environment as they age on soils and sediments. The result is that the mitigation actually needed to protect the environment may be much less than regulations require. Selective analytical methods based on supercritical fluid extraction were developed to determine the concentrations of PAHs in soils and sediments that are actually available for environmental processes and, therefore, an environmental concern. These methods were then extended to determine the bioavailability of other hydrophobic pollutants, primarily PCBs. It was demonstrated that SFE applies to PCBs in a manner analogous to PAHs; i.e., that it distinguishes different degrees of binding that occur in different sediments. The similarity in SFE behavior for PCBs and PAHs supports the hypothesis that SFE is a useful method for predicting the bioavailability of PCBs and, potentially, other hydrophobic organic pollutants. A method to determine PCBs in sediment pore water based on solid-phase microextraction was also developed that is capable of determining low $\mathrm{pg} / \mathrm{mL}$ concentrations with water samples as small as $1.5 \mathrm{~mL}$.

Hawthorne, S.B. Subtask 1.20 - Development of Methods to Determine the Environmental Availability of PAHs, PCBs, and Petroleum Hydrocarbons; Final Report (Jan 4, 2005 June 30, 2007) for U.S. Department of Energy Cooperative Agreement No. DE-FC2698FT40320; EERC Publication 2007-EERC-05-02; Energy \& Environmental Research Center: Grand Forks, ND, May 2007.

\section{Subtask 1.21 - Optimization of Hydrogen Enrichment for Subsurface Delivery}

The accepted practice of using direct gaseous injection of hydrogen for in situ reductive dechlorination of soil contamination is limited by the low solubility of hydrogen and the short residence time for hydrogen absorption, as well as by safety concerns pertaining to hydrogen buildup in the wellhead. Hydrogen is also utilized as an electron donor by aerobic bacteria, and it can be used to initiate the dechlorination process by turning aerobic sites anaerobic. This subtask designed and tested a hydrogen enrichment process that dissolves hydrogen in a carbon substrate mixture as a carrier and injects it using a modified mobile injection system. The low-pressure gas contactor allowed for better and safer process control and extended residence time. An optimized 
solubility over $2 \mathrm{mg} / \mathrm{L}$ was measured in the process under development, whereas the maximum reported solubility limit for hydrogen in water is $1.6 \mathrm{mg} / \mathrm{L}$.

In situ enhanced reductive dechlorination has gained considerable acceptance by regulatory agencies and environmental industry worldwide. It has also become increasingly evident that the primary constraints for remediation of complex sites are associated more with reagent delivery and residence time in the target in situ zone than with reaction chemistry itself. Hydrogenenhanced dechlorination has highly favorable stoichiometry and tolerance for reaction process inefficiencies. A reduction of $1 \mathrm{mg} / \mathrm{L}$ of dissolved hydrogen by dechlorination bacteria results in degradation of $21 \mathrm{mg} / \mathrm{L}$ of PCE (perchloroethylene). Hydrogen is also utilized as an electron donor by aerobic bacteria and can be used to initiate the dechlorination process and turn the aerobic sites anaerobic. Together with the optional use of food-grade carbon substrate, the suggested method is inexpensive, safe, flexible, and environmentally acceptable.

The direct gaseous injection of hydrogen in support of in situ reductive dechlorination is limited by its low solubility and short residence time, including safety concerns pertaining to hydrogen wellhead buildup. The EERC project focused on design and demonstration of an ex situ hydrogen enrichment process using a modified mobile injection system and a carbon substrate mixture as hydrogen carrier. Our results suggest that ex situ hydrogen enrichment in a low-pressure gas contactor allows for better hydrogen enrichment process control and extended residence time. While the maximum reported solubility limit for hydrogen in water is $1.6 \mathrm{mg} / \mathrm{L}$, solubility over $2 \mathrm{mg} / \mathrm{L}$ was detected in our proof-of-concept samples after a simple and inexpensive change of the controlling factors. Its concentration is a function of both the hydrogen feed rate and dissolved organic carbon content in the feed mixture. In both cases, dissolved hydrogen appears to increase until it reaches an optimal level of the respective parameters, and a further increase in either hydrogen feed rate or dissolved organic carbon does not translate into an increase in dissolved hydrogen concentration.

With respect to fast in situ reactions with contaminant (such as chlorinated hydrocarbon) and favorable stoichiometry, and regardless of its volatility and losses between the point of enrichment and point of delivery, hydrogen enrichment of the injection mixture represents a technique that will accelerate in situ contaminant reduction.

Solc. J. Subtask 121 - Optimization of Hydrogen Enrichment for Subsurface Delivery; Final Report for U.S. Department of Energy Cooperative Agreement No. DE-FC26-98FT40320; EERC Publication 2006-EERC-07-03; Energy \& Environmental Research Center: Grand Forks, ND, July 2006.

\section{Subtask 1.22 - Microbial Cycling of $\mathrm{CH}_{4}, \mathrm{CO}_{2}$, and $\mathrm{N}_{2} \mathrm{O}$ in Wetland Environments}

Laboratory column studies were designed to simulate soil microbial activity in both farmed and restored wetlands to determine the role that microbial action plays in determining $\mathrm{CO}_{2}, \mathrm{CH}_{4}$, and $\mathrm{N}_{2} \mathrm{O}$ fluxes in aerobic and anoxic ecosystems respectively. The laboratory study was conducted in collaboration with field monitoring performed by USGS Northern Prairie Wildlife Research Center to verify and evaluate $\mathrm{CO}_{2}$ sequestration potential by wetland restoration in the Prairie Pothole Region (PPR). In addition, remote sensing by satellite imagery was investigated 
as a means of detecting soil gas flux from wetlands. Comparison of the gas fluxes observed in the laboratory for farmed and wetland conditions indicated that restoration of PPR wetlands would sequester atmospheric $\mathrm{CO}_{2}$ and would not promote the release of either $\mathrm{N}_{2} \mathrm{O}$ or $\mathrm{CH}_{4}$. Application of ammonia increased the emission of both $\mathrm{N}_{2} \mathrm{O}$ and $\mathrm{CH}_{4}$ in the laboratory study, indicating that eliminating the nitrogen fertilizer applied to farmland by restoring wetlands would actually reduce both $\mathrm{N}_{2} \mathrm{O}$ and $\mathrm{CH}_{4}$ emissions. The emission of $\mathrm{CO}_{2}$ in the laboratory study was increased by the addition of ammonia, which suggests that the application of nitrogen fertilizer to farmland may be causing an overlooked increase in $\mathrm{CO}_{2}$ emissions. Calculations based on the laboratory results indicated that the overall reduction in global warming potential by wetland restoration would be mainly contributed by the reduction in $\mathrm{CO}_{2}$ emission. The results of remote sensing indicated that the 15-meter resolution of the imagery was sufficient to define multiple zones in large regions of wetlands; however, it was not sufficient to correlate with gas flux measurements within the smaller wetland sites ( $<250$ meters) evaluated by this task.

Kurz, B.A.; Ye, D.; Kurz, M.D. Subtask 1.22 - Microbial Cycling of $\mathrm{CH}_{4}, \mathrm{CO}_{2}$, and $\mathrm{N}_{2} \mathrm{O}$ in a Wetlands Environment; Final Report (Mar 1, 2006 - Dec 31, 2008) for U.S. Department of Energy Cooperative Agreement No. DE-FC26-98FT40320; EERC Publication 2009-EERC02-08; Energy \& Environmental Research Center: Grand Forks, ND, Feb 2009.

\section{Subtask 1.23 - Mercury Removal from Barite for the Oil Industry}

Drilling muds are used by the oil industry to provide a seal and to float rock chips to the surface during the drilling process. Barite (naturally occurring barium sulfate ore) is commonly used as a weighting agent additive in drilling muds because it is chemically nonreactive and has a high specific gravity (between 4.2 and 4.25 at $20^{\circ} \mathrm{C}$ ). Because of environmental concerns, barite used in the Gulf of Mexico must be certified to contain less than $1 \mathrm{mg} / \mathrm{kg}$ of mercury. Some barites have been confirmed to contain mercury concentrations above $10 \mathrm{mg} / \mathrm{kg}$. Faced with regulation, the U.S. Gulf Coast oil industry has looked to foreign sources of low-mercury barite, primarily India and China. These sources have high-grade barite deposits; however, U.S. purchasers pay high costs for shipping to U.S. grinding plants. The objective of this project was to demonstrate two mercury removal techniques for high-mercury barite sources. The mercury content of two barite samples from different sources was reduced to the required level by either chemical treatment with dilute acid or thermal treatment. An economic analysis indicates that the treatment to remove mercury would not significantly add to the cost of barite processing, making higher-mercury barite a viable alternative to more expensive barite sources that contain lower concentrations of mercury.

Holmes, M.J.; Nyberg, C.M.; Hill Brandt, K.L.; Eylands, K.E.; Fiala, N.J.; Dunham, G.E. Subtask 1.23 - Mercury Removal from Barite for the Oil Industry; Final Report (Apr 1, 2006 - June 30, 2007) for U.S. Department of Energy Cooperative Agreement No. DEFC26-98FT40320; EERC Publication 2008-EERC-09-03; Energy \& Environmental Research Center: Grand Forks, ND, Sept 2008. 


\section{Subtask 1.24 - Optimization of Cooling Water Resources for Power Generation}

This subtask developed an interactive, Web-based decision support system (DSS C 2007 EERC Foundation) to provide power generation utilities with an assessment tool to address water supply issues when planning new or modifying existing generation facilities. The DSS integrates water and wastewater treatment technology and water law information with a GIS-based interactive map that links to state and federal water quality and quantity databases for North Dakota, South Dakota, Minnesota, Wyoming, Montana, Nebraska, Wisconsin, and Iowa.

Kurz, B.A.; Peck, W.D.; Shockey, R.A.; Stepan, D.J. Subtask 1.24 - Optimization of Cooling Water Resources for Power Generation; Final Report (May 16, 2007 - Mar 31, 2009) for U.S. Department of Energy Cooperative Agreement No. DE-FC26-98FT40320; EERC Publication 2009-EERC-03-07; Energy \& Environmental Research Center: Grand Forks, ND, March 2009.

\section{TASK 2.0 - AIR QUALITY ASSESSMENT AND CONTROL}

\section{Subtask 2.1 - Value-Added Sorbent Development for Mercury Control}

Comparison of mercury sorption on different types of carbon indicates that the chemistry of the carbon surface is more important than surface area. Activated carbons derived from lignite exhibited superior sorption properties, with higher sodium content and, to a lesser degree, calcium content having a beneficial effect. Lignite coals contain a variety of associated minerals including pyrite $\left(\mathrm{FeS}_{2}\right)$, quartz $\left(\mathrm{SiO}_{2}\right)$, anhydrite $\left(\mathrm{CaSO}_{4} \cdot \mathrm{xH}_{2} \mathrm{O}\right)$, and a diversity of aluminosilicates. In addition, lignites contain inorganics $(\mathrm{Ca}, \mathrm{K}, \mathrm{Na})$ present in the pore moisture or bound directly to carboxylic acid functional groups on the carbon matrix. During the activation process, these inorganics are changed to finely divide inorganic compounds such as $\mathrm{CaO}$ and $\mathrm{Na}_{2} \mathrm{O}$. Pyrite is initially converted to other sulfides such as greigite (FeS), which are highly reactive in air, forming iron sulfate. No correlation between mercury capture and inorganic content was identified in tests where the inorganic content of commercial Norit activated carbon was progressively removed by washing with a series of reagents.

The mechanism for the oxidation and capture of mercury emissions by injection of activated carbon was shown to be critically affected by interactions with $\mathrm{SO}_{2}, \mathrm{HCl}, \mathrm{NO}, \mathrm{NO}_{2}$ and moisture in flue gas. Higher concentrations of $\mathrm{SO}_{2}$ progressively inhibit capture in the presence of moisture, but not in its absence. $\mathrm{SO}_{2}$ has no effect on mercury oxidation. All combinations of $\mathrm{HCl}, \mathrm{NO}$, and $\mathrm{NO}_{2}$ improved mercury capture in the absence of $\mathrm{SO}_{2}$. Activated carbon does not exhibit an appreciable capacity for mercury capture unless the carbon has been exposed to $\mathrm{HCl}$ or $\mathrm{NO}_{2}$. Mercury oxidation continues to take place across a carbon bed even after the mercury capacity of the carbon had been saturated and capture has ceased. An understanding of the reactions involved has been aided by surface analysis by x-ray photoelectron spectroscopy (XPS) and quantum mechanical calculation of binding energies on carbon structures. The mechanism that has evolved to explain these findings involves the oxidation of mercury by $\mathrm{NO}_{2}$ or other oxidizing gases on carbon oxidation sites formed by prior reactions of $\mathrm{HCl}$ or $\mathrm{NO}_{2}$ with basic zigzag edge structures on the carbon. The oxidized mercury $\left(\mathrm{Hg}^{\mathrm{II}}\right)$ remains bound to the 
oxidation site unless the site is already occupied by nonvolatile $\mathrm{SO}_{4}{ }^{-2}$ formed by the oxidation of $\mathrm{SO}_{2}$ in the presence of moisture and $\mathrm{NO}_{2}$. Competition for capture sites explains the inhibiting effect of $\mathrm{SO}_{2}$ on capture and also the cessation of capture and the release of oxidized mercury such as $\mathrm{HgCl}_{2}$ or $\mathrm{Hg}\left(\mathrm{NO}_{3}\right)_{2}$ during the continued oxidation of mercury on the carbon surface.

Dunham, G.E.; Olson, E.S.; Miller, S.J. Subtask 2.1 - Value-Added Sorbent Development for Mercury Control; Final Report for U.S. Department of Energy Cooperative Agreement No. DE-FC26-98FT40320; EERC Publication 00-EERC-07-05; Energy \& Environmental Research Center: Grand Forks, ND, July 2000.

\section{Subtask 2.2 - Fine Particulate (PM 2.5$)$ Characterization and Source Apportionment}

A sampling trailer outfitted with state-of-the-art instrumentation was used to collect particulates from ambient air in rural and urban locations and in proximity to farms and industrial facilities to correlate size and composition for the purpose of source apportionment and determination of health effects. Sampling included collection of time-differentiated particulates that could be directly analyzed by scanning electron microscopy (SEM) methods.

Computer programs were developed for automating SEM for imaging, sizing, and analyzing individual particles as small as $0.5 \mu \mathrm{m}$, including automated capabilities for determining size distribution and chemical composition in relation to size. Additional characterization of ambient particulates was performed using aerodynamic and scanning mobility particle sizers (APS-SMPS) and extractive fractionation. Statistical cluster analysis was used to identify different categories of fine particulates variously enriched in spores, pollen, soil particles, soot, unclassified organic material, fugitive dust, identifiable minerals (e.g., clay, quartz, carbonates, and feldspars), or secondary sulfates depending on weather conditions and proximity to gravel roads, agricultural operations, fires, power plants, oil refineries, and gasification plants.

A series of toxicological assays was performed on fractionated extracts of wood smoke, diesel exhaust, coke emissions, urban air, and indoor air particulate matter (PM). The method developed for this activity separated extractable PM constituents (organic carbon, metals, and inorganic salts) into four different polarity fractions by extracting with subcritical water at different temperatures. Each fraction was analyzed to determine total extractable mass, elemental composition (CHN), and organic components identifiable by gas chromatography-mass spectroscopy (GC-MS). Three different toxicity tests were used based on 1) mitochondrial respiration, 2) DNA damage, and 3) viability of mammalian cells. The results showed a significant contribution from polar and midpolarity fractions, which is in contrast to typically studied nonpolar PAHs. This work contributed to collaborative research that is beginning to characterize properties of $\mathrm{PM}_{2.5}$ besides size alone that are implicated in health effects.

Benson, S.A.; Crocker, C.R.; Gallagher, J.R.; Kubatova, A.; Zhuang, Y.; Galbreath, K.D.; Eylands, K.E.; Jensen, R.R.; Laumb, J.D.; McCollor, D.P.; Miller, S.J.; Olderbak, M.R.; Helmowski, B.S. Subtask 2.2 - Fine Particulate $\left(P_{2.5}\right)$ Characterization and Source Apportionment; Final Report for U.S. Department of Energy Cooperative Agreement No. 
DE-FC26-98FT40320; EERC Publication 05-EERC-01-04; Energy \& Environmental Research Center: Grand Forks, ND, Jan 2005.

\section{Subtask 2.3 - Carbon Dioxide Sequestering}

Bench-scale research was performed to evaluate the use of microalgae to capture $\mathrm{CO}_{2}$ directly from stack gas from a coal-fired power plant, either for sequestration or for production of fuels, chemicals, and animal feed. $\mathrm{CO}_{2}$ mass transfer from flue gas to the algal growth medium was modeled using the Facility for the Analysis of Chemical Thermodynamics (FACT) code to predict equilibrium concentrations. The equilibrium model predicted that the $\mathrm{CO}_{2}, \mathrm{SO}_{2}$ and $\mathrm{NO}$ in the flue gas would be in equilibrium with concentrations in the growth liquor at a gasto-liquid ratio of $3: 1$ and that approximately $50 \%$ of the $\mathrm{CO}_{2}$ would be in the liquid phase at a gas:liquid ratio of $6: 1$. Some growth inhibition was observed with direct sparging of simulated flue gas containing $\mathrm{SO}_{2}$ into the growth reactors, and the $\mathrm{pH}$ was adjusted to neutralize absorbed $\mathrm{SO}_{2}$ and $\mathrm{NO}_{\mathrm{x}}$. A different strain of algae, Monoraphidium and Nannochloris, has been reported to be resistant to $\mathrm{SO}_{2}$ under flue gas conditions. An engineering study estimated that a pond for growing algae to capture $\mathrm{CO}_{2}$ from a coal-fired power plant would be technically feasible within practical limits on pond and equipment sizes and would be economical at an estimated cost of $\$ 30$ per ton of carbon.

Stepan, D.J.; Shockey, R.E.; Moe, T.A.; Dorn, R. Subtask 2.3 - Carbon Dioxide Sequestering Using Microalgal Systems; Final Report (Apr 15, 1998 - Nov 30, 2001) for U.S. Department of Energy Cooperative Agreement No. DE-FC26-98FT40320; EERC Publication 2002EERC-02-03; Energy \& Environmental Research Center: Grand Forks, ND, Feb 2002.

\section{Subtask 2.4 - Evaluating Short-Term Climate Variability in the Late Holocene of the Northern Great Plains}

The anthropogenic effects of industrial, agricultural, and domestic activities on climate change are best understood in the context of natural climate variations. In this subtask, an extensive review of literature was performed to investigate the possibility of integrating shortterm climate data used for trend analysis and modeling with long-term information from studies on geology and paleontology over the Holocene period of the last 10,000 years and extending back millions of years. Examination of evidence of changes in the biotic and physical histories preserved in the sediment or rock record can be interpreted to identify trends and patterns in climate on a scale that greatly extends the historical record. In midcontinental areas of generally stable semiarid climate, wetting and drying of sediment drastically affect alluvial and eolian processes. Past studies of these areas can be used to establish a framework for understanding climate change and for performing regional comparisons. For example, episodes of alluvial aggradation, as represented by discrete accumulations of floodplain at various elevations and ages, suggest that warm and dry conditions prevail during the aggradational process. Episodes of valley downcutting suggest the opposite, that cool and moist conditions prevail during periods of alluvial degradation. The aggradation and degradation of windblown sediments (i.e., eolian deposits) follow this same basic pattern. The key to interpreting these and other changes is our ability to construct higher-resolution time scales to determine rate and extent of climate change. Many useful studies showing general climate trends have been conducted, but they do not have 
the power to resolve smaller variations in climate that play a significant role in events such as drought or flooding that occur apart from a major climate shift. To improve spatial and temporal correlations, a methodology based on "climate sections" is proposed to integrate data relating to the climate history of a region with increasing accuracy with progressive study and scientific advancement. This idea is analogous to concepts used in stratigraphic studies on a particular formation, range of fossil occurrence, or time boundary. Correlations from one area to another are based on selected criteria, allowing events in space and time to be placed into coherent histories.

Hartman, J.H. Subtask 2.4 - Evaluating Short-Term Climate Variability in the Late Holocene of the Northern Great Plains; Final Report (Apr 15, 1998 - July 31, 1999) for U.S. Department of Energy Cooperative Agreement No. DE-FC26-98FT40320; Energy \& Environmental Research Center: Grand Forks, ND, Sept 2009.

\section{Subtask 2.5 - Emission Control for Diesel Systems}

Proof of concept was developed for a new particulate control technology for diesel engines based on the hybrid combination of electrostatic precipitation (ESP) and barrier filtration previously used in the EERC's patented advanced hybrid particulate collector (AHPC). Benchscale tests achieved collection efficiencies $>99 \%$ at a low pressure drop of less than 1 inch of water. High efficiencies were achieved across the entire particle-size distribution for representative ranges of exhaust temperature and filtration velocity. Results were confirmed in tests on a 160-hp diesel engine.

Almlie, J.C.; Zhuang, Y.; Miller, S.J. Subtask 2.5 - Emission Control for Diesel Systems; Final Report (Apr 1, 2003 - Mar 31, 2006) for U.S. Department of Energy Cooperative Agreement No. DE-FC26-98FT40320; EERC Publication 06-EERC-05-03; Energy \& Environmental Research Center: Grand Forks, ND, May 2006.

\section{Subtask 2.6 - Measuring Particulate Levels at High Altitudes Downgradient from Anthropogenic Sources}

The goal of this project was to determine if weather balloons could be used to obtain particulate concentration data at various altitudes, downgradient from an anthropogenic source, allowing the creation of vertical distribution profiles for these air contaminants. The project could not be implemented and was canceled.

\section{Subtask 2.7 - Examination of Mercury Sources in the Domestic Oil and Gas Industry}

Advanced analytical methods were employed to quantify the occurrence and distribution of mercury in barite. Barite is a common component of drilling fluid used by the petroleum exploration and production industry. The results of previous work by others had suggested that the mercury in barite was associated with sulfide minerals, particularly the zinc sulfide mineral sphalerite, that occur as minor components $(<1 \%$ by weight) in the barite matrix. The results of work conducted by the EERC on samples from the same source indicated that the mercury is not associated primarily with sulfides but is associated with a number of mineral phases, including 
feldspar clay, pyrite, hematite, hyalophane, and barite. The analyses performed included the ASTM International acid extraction/cold-vapor atomic absorption method, x-ray fluorescence (XRF), SEM techniques, and a sequential leaching study. The release of mercury was only achieved through rigorous acid treatments. This suggests that the bioavailability of mercury associated with barite-based drilling mud is more complex than previously thought and that the mercury may not be released into the marine environment.

Eylands, K.E.; Benson, S.A.; Sorensen, J.A. Subtask 2.7 - Examination of Mercury Sources in the Domestic Oil and Gas Industry; Final Report (Apr 1, 2003 - Dec 2004) for U.S. Department of Energy Cooperative Agreement No. DE-FC26-98FT40320; EERC Publication 2005-EERC-11-01; Energy \& Environmental Research Center: Grand Forks, ND, Nov 2005.

\section{Subtask 2.8 - Control of Trace Elements in Gasification Systems}

Sorbents were evaluated for capturing mercury from a reducing gas at $300^{\circ}$ to $400^{\circ} \mathrm{C}$. Bench-scale tests were conducted by passing a stream of $10 \mathrm{vol} \%$ hydrogen in nitrogen containing $34.8 \mu \mathrm{g} / \mathrm{m}^{3}$ of $\mathrm{Hg}^{0}$ through a thin fixed bed of granular sorbent and observing the mercury concentration in the effluent to the point of breakthrough where capture ceased. Zinc sulfide and zinc selenide sorbents provided good mercury capture at $300^{\circ}$ but were less effective at $350^{\circ} \mathrm{C}$. Two proprietary sorbents performed very well at the higher temperatures, continuing to capture $>95 \%$ at $350^{\circ} \mathrm{C}$ after 2 hours, whereas $\mathrm{ZnSe}, \mathrm{ZnS}$, and $\mathrm{CuS}$ sorbents exhibited breakthrough after only a few minutes at $350^{\circ} \mathrm{C}$. Additional tests were performed on halogenated carbon prepared by treating activated carbon with bromine or hydrogen bromide. Activated carbon treated with bromine in dichloromethane provided $>94 \%$ capture over a period of 3 hours at temperatures up to $400^{\circ} \mathrm{C}$, where the untreated activated carbon exhibited immediate breakthrough at $350^{\circ} \mathrm{C}$. The high capacity of the bromine-treated sorbents is attributed to the high strength of the bromine-mercury bond, which resists the hydrogenolysis that occurs at lower temperatures with mercury oxides and oxysalts. Other halogenated carbons gave similar results. In comparing various sorbents, it was evident that the method of preparation was important as well as composition.

Gorecki, C.D.; Sorensen, J.A.; Bremer, J.M.; Ayash, S.C.; Knudsen, D.J.; Holubnyak, Y.I.; Smith, S.A.; Steadman, E.N.; Harju, J.A. Subtask 2.8 - Control of Trace Elements in Gasification Systems; Final Report (Aug 25, 2008 - June 30, 2009) for U.S. Department of Energy Cooperative Agreement No. DE-FC26-98FT40320; EERC Publication 2009-EERC07-06; Energy \& Environmental Research Center: Grand Forks, ND, July 2009.

\section{Subtask 2.9 - Fraction of Organics from Air Particulates with Subcritical Water}

A significant portion of the constituents in PM, mainly polar compounds, remain to be identified. Toxicological studies have been mainly limited to known compounds. In this study, extractions of PM constituents using subcritical hot pressurized water (e.g., $100^{\circ}$ to $150^{\circ} \mathrm{C}$ ) were performed to separate fractions of different polarity, including neglected polar compounds. Instead of targeting individual compounds, toxicological assays were performed on a range of polarity fractions. Two in vitro assays evaluating oxidative stress and genotoxicity were adopted 
to approximate possible adverse health effects to the human respiration system. PM samples from diesel exhaust, wood smoke, and ambient Pittsburgh air influenced by coke emissions all induced oxidative stress in murine macrophages (immune cells). Comparable results were also obtained for human bronchial epithelial cells. As expected, the results demonstrated a significant contribution from polar and midpolar fractions. The oxidative stress caused by wood smoke PM fractions was linked to oxygenated polyaromatics. The comparison of subcritical water fractions from two ambient Pittsburgh PM samples (with and without coke emission influence) showed that various polarity fractions of both exhibited genotoxicity, suggesting that different constituents were responsible for toxicity. The genotoxicity of diesel exhaust PM was shown to be higher in the presence of an oxidizer than without. The sum of the data generated confirmed the toxicological importance of typically neglected polar PM fractions. In addition, the data demonstrated that even samples of slightly different origin, such as the two diesel PM samples or the two PM samples from ambient air in Pittsburgh, may have different toxicological impacts and that the conditions under which PM was generated significantly influenced its toxicity.

Kubatova, A. Subtask 2.9 - Fraction of Organics from Air Particulates with Subcritical Water Final Report (Apr 1, 2003 - May 31, 2004) for U.S. Department of Energy Cooperative Agreement No. DE-FC26-98FT40320; EERC Publication 2004-EERC-06-02; Energy \& Environmental Research Center: Grand Forks, ND, June 2004.

\section{Subtask 2.10 - Advanced Fine Particulate Characterization Methods}

This subtask combined work on several different activities performed for the purposes of 1) improving methods for characterizing inorganic and carbonaceous constituents in atmospheric pariculates from power plants and other sources to predict source apportioment and 2) modeling the interactions of mercury on activated carbon.

Activity 1 - New methods were developed for performing automated SEM analysis of chemical and morphologic properties. The new software lists the results of point analysis either by element or oxide weight percent and labels locations of the points on the image. Samples were collected and analyzed from various pilot-scale particulate control devices downstream of the EERC's particulate control combustor burning PRB coal. The sample from the ESP alone contained particles rich in calcium sulfate and some aluminosilicate. The sample from a baghouse downstream of an ESP contained relatively few calcium-rich particles. The sample from a spray dryer absorber/ESP combination was rich in calcium and contained a minor amount of sodium, and the sample from a spray dryer/fabric filter combination was rich in calcium.

Activity 2 - Analytical methods are being developed to differentiate the major organic carbon fractions and the metals and inorganic salts in these fractions. The significance of organic PM differentiation based on polarity is in linking the PM to primary (nonpolar) and secondary (polar) aerosol sources. Extraction with hot pressurized water by the method used in Subtask 2.9 was used to separate polar organic carbon, and methylene chloride was employed for the extraction of nonpolar organics. For diesel exhaust, the midpolarity fraction was largest. In both wood smoke and urban PM, the polar, midpolar, and nonpolar fractions were evenly distributed. The results on the distribution of polar and midpolar organics were supported by near-edge x-ray absorption fine structure (NEXAFS) spectroscopy, which differentiates various carbon bonds. 
The results confirmed that polar compounds represent a significant portion of PM from different sources and that this fraction, which is neglected in most studies, needs further research attention. Two ion chromatographic methods were used to speciate metals. The first method using 4-2(2-pyridylazo)resorcinol as a derivatizing agent at $535 \mathrm{~nm}$ determined the transition metals $\mathrm{Pb}^{2+}, \mathrm{Fe}^{3+}, \mathrm{Cu}^{2+}, \mathrm{Ni}^{2+}, \mathrm{Co}^{2+}, \mathrm{Cd}^{2+}, \mathrm{Mn}^{2+}$, and $\mathrm{Fe}^{2+}$ at a detection of $100 \mathrm{ppb}$ (except $500 \mathrm{ppb}$ for $\mathrm{Pb})$. The second method employed 2-[(5-bromo-2-pyridyl)-azo]-5-diethylaminophenol as a derivatizing agent, which allows for determination of $\mathrm{Pb}^{2+}, \mathrm{Cu}^{2+}, \mathrm{Ni}^{2+}, \mathrm{Co}^{2+}$, $\mathrm{Cd}^{2+}, \mathrm{Mn}^{2+}$, and $\mathrm{Hg}^{2+}$ at detection limits of $25 \mathrm{ppb}$ for most of the metals.

Activity 3 - Quantum modeling using density functional theory (DFT) calculations was used to elucidate a recently developed mechanistic model for mercury speciation in coal combustion systems and interactions on activated carbon. Reaction energies, enthalpies, free energies, and binding energies of $\mathrm{Hg}$ species to the prototype molecules were derived from the data obtained in these calculations. Bimolecular rate constants for the various elementary steps in the mechanism were estimated using the hard-sphere collision theory approximation, and the results seemed to indicate that extremely fast kinetics could be involved in these surface reactions, suggesting that significant improvements in carbon capture technology by activated carbon injection may be possible.

Activity 4 - Activated carbon made from high-potassium biomass blended with coal was tested to determine its activity for catalyzing $\mathrm{NO}_{\mathrm{x}}$ reduction in flue gas. Because of the large amounts of $\mathrm{CO}$ formed in the reduction process, these tests were suspended in favor of developing a carbon sorbent for mercury control on boilers burning high-sulfur coals. The hypothesis was that the alkali and alkaline-earth elements would remove $\mathrm{SO}_{2}$ and $\mathrm{SO}_{3}$ that would otherwise be adsorbed on the active sites and impede mercury capture. The raw materials utilized were high-sodium North Dakota lignite and high-potassium sunflower hulls. The activated carbon produced from the blend had a very high surface area. However, pilot-scale tests injecting this activated carbon upstream of a pilot-scale ESP indicated that the capture of mercury from bituminous coal-derived flue gas was only $15 \%$ at an injection rate of $6 \mathrm{lb} /$ Macf. Results for this activated carbon showed that the active sites on the carbon were poisoned by $\mathrm{SO}_{2}$ and $\mathrm{SO}_{3}$ despite the alkali and alkaline-earth elements that were present.

Benson, S.A.; Kong, L.; Eylands, K.E.; Azenkeng, A.; Laumb, J.D.; Jensen, R.R.; Olson, E.S.; Mackenzie, J.M.; Rokanuzzaman, A.M. Subtask 2.10 - Advanced Fine Particulate Characterization; Final Report (Apr 1, 2004 - Jan 31, 2007) for U.S. Department of Energy Cooperative Agreement No. DE-FC26-98FT40320; EERC Publication 2007-EERC-05-11; Energy \& Environmental Research Center: Grand Forks, ND, May 2007.

\section{Subtask 2.11 - Staged Electrostatic Precipitator}

A prototype of a staged ESP was designed, fabricated, and tested on two different combustion coal flue gases with different fly ash resistivities. Particulate sampling data, including APS, SMPS, and EPA Method 5 data, were collected to determine the PM emissions of the staged ESP configurations compared to a conventional ESP configuration. Test results showed an additional $30 \%$ to $70 \%$ reduction in total PM emission for staged ESPs in flue gas with medium- to high-resistivity fly ashes. For the ultrafine particles in the range from 0.02 to 
$0.1 \mu \mathrm{m}$, emissions with the staged configuration were about an order of magnitude lower. About $90 \%$ of current coal-fired utility boilers in the United States are equipped with dry ESPs, many of which are not adequate to control $\mathrm{PM}_{2.5}$ emissions to required levels because of the inherently lower collection efficiency of an ESP for finer particles. The staged ESP is based on a simple design that can be retrofitted on existing plants to provide high collection efficiency without compromising reliability.

Almlie, J.C.; Zhuang, Y.; Miller, S.J. Subtask 2.11 - An Investigation into the EERC Staged Electrostatic Precipitator Concept; Final Report (Jan 1, 2005 - Mar 31, 2008) for U.S. Department of Energy Cooperative Agreement No. DE-FC26-98FT40320; EERC Publication 2008-EERC-05-08; Energy \& Environmental Research Center: Grand Forks, ND, May 2008.

\section{Subtask 2.12 - Advanced Characterization and Classification of Particulate Matter}

This study extended analytical capabilities for characterizing fine respirable particulates. Improved software was developed to perform particle-by-particle analysis by computercontrolled scanning electron microscopy (CCSEM) using an energy-dispersive spectrometer to determine size, morphology, and chemical composition with a fully automated pixel-by-pixel point analysis capability. Analysis can be performed for elements with an atomic number as low as sodium. Electron backscatter diffraction (EBSD) was further added to identify crystalline materials and their chemical composition and to discriminate between crystal compositions down to $\sim 0.5 \mu \mathrm{m}$ in size. The new system makes it possible to determine if an element is in an oxidized state, but not to determine the degree of oxidation. The new software also stores higherresolution digital images of the analyzed particles. These methods form the basis for classifying atmospheric particulates to distinguish between primary particles from sources such as road dust or power plant fly ash and secondary particles of sulfate and nitrate formed from gaseous emissions of $\mathrm{SO}_{2}$ and $\mathrm{NO}_{\mathrm{x}}$.

Raymond, L.J. Subtask 2.12 - Advanced Characterization and Classification of Particulate Matter; Final Report (Jan 15, 2005 - June 30, 2007) for U.S. Department of Energy Cooperative Agreement No. DE-FC26-98FT40320; EERC Publication 2007-EERC-10-01; Energy \& Environmental Research Center: Grand Forks, ND, Oct 2007.

\section{Subtask 2.13 - Advanced Hybrid Particulate Collector Fundamental Performance}

A review was completed with support of an independent outside consultant on the performance of the full-scale advanced hybrid particulate collector (AHPC) demonstration at the Big Stone Power Plant. The AHPC technology which combines ESP and fabric filter elements in a cost-effective compact design was developed and patented by the EERC. It had been shown to provide greater than $99.99 \%$ particulate collection efficiency in extensive pilot- and demonstration-scale tests. The review findings at the Big Stone Plant showed that there were significant alignment problems with the discharge and collection electrodes in the first fields, which had been retrofitted into the advanced hybrid configuration in the second phase of the demonstration. In the original configuration, only the back three fields were retrofitted in the advanced hybrid configuration. The alignment problems led to excessive sparking and shutdown 
of the high-voltage power for the first fields. The recommendation to management at the Big Stone plant was that the alignment deficiencies be corrected before further evaluating the performance of the AHPC.

Miller, S.J. Subtask 2.13 - Advanced Hybrid Particulate Collector Fundamental Performance; Final Report (Mar 1, 2006 - June 30, 2007 for U.S. Department of Energy Cooperative Agreement No. DE-FC26-98FT40320; Energy \& Environmental Research Center: Grand Forks, ND, July 2007.

\section{TASK 3.0 - ADVANCED POWER SYSTEMS}

\section{Subtask 3.1 - Low-Temperature Ash Sintering/Strength}

Significant progress had been made previously in understanding and predicting ash deposition on heat exchange surfaces, but methods for estimating deposit removal by soot blowing were lacking. Studies on deposit sintering and strength development were performed to predict ease of deposit removal using a heated-stage microscope (HSM) to observe the growth of the neck formed between two touching particles as they sinter. In past studies, viscosities calculated from HSM sintering studies using the Frenkel model compared fairly well with values predicted by a modified Urbain viscosity model that calculated viscosity based on ash composition and temperature. In this subtask, HSM tests were performed on ashes derived from three coals and two biomass fuels and on a standard soda-lime glass. The HSM measurements were used to calculate the viscosity of liquid phases as the sintering progressed using the Frenkel model. However, in this study it was not possible to correlate Frenkel viscosities based on the HSM results with either the Urbane viscosity model or the FACT thermodynamic model. Future development of a practical method for modeling sintering and strength development will require direct measurements of viscosity on ashes of varying composition in a higher range of viscosity to extend the range of the Urbane model for predicting viscosity from data on ash composition and temperature. Extending the Urbane model can provide the basis for further correlating laboratory measurements of viscosity with sintering and deposit strength to predict ease of deposit removal.

Zygarlicke, C.J.; McCollor, D.P.; Kay, J.P. Subtask 3.1 - Low-Temperature Ash Sintering/Strength; Final Report (July 1, 1998 - June 30, 1999) for U.S. Department of Energy Cooperative Agreement No. DE-FC26-98FT40320; Energy \& Environmental Research Center: Grand Forks, ND, Oct 1999.

\section{Subtask 3.2 - Characterization and Prediction of Ash Emissivity}

Western subbituminous coals generate highly reflective ash that reduces heat transfer in the radiant zone of a pulverized-fuel boiler. Ash emissivity and reflectivity are primarily determined by particle size, with the reflectivity of deposits from subbituminous coals resulting from an abundance of very small refractory ash particles rich in $\mathrm{CaO}$ and $\mathrm{MgO}$ or from fine sulfate materials such as $\mathrm{Na}_{2} \mathrm{SO}_{4}$. Biomass fuels and biomass-coal blends are expected to experience similar reflectivity issues owing to organically associated calcium and potassium that are 
transformed during combustion into fine oxides and sulfates. The ability to experimentally determine and predict ash emissivity from coal mineralology would fundamentally advance the understanding of boiler heat transfer and serve as a basis for increasing thermal efficiency. The objective of this task was to develop a standard laboratory protocol to measure ash emissivity using FT-IR (Fourier transform infrared) spectroscopy. Spectral and temperature data were collected on five size-segregated fractions of fly ash samples from six coals at $20^{\circ}$, $400^{\circ}, 610^{\circ}$, and $925^{\circ} \mathrm{C}$. Fly ash samples collected from bench-scale combustion tests on four subbituminous and two bituminous coals were aerodynamically sized in a multicyclone collector into size fractions with $\mathrm{d}_{50}$ cut points of $8.6,4.8,2.5,1.8$, and $0.8 \mu \mathrm{m}$. The expected trend of lower emission for smaller particle-size fractions was observed in the experimental data, although there was considerable scatter in the data. Sintering of the ash was believed to account for much of the variability in the emission measurements, although this could not be directly correlated with calculated ash properties such as viscosity and percentage of liquid-phase material. Particle size appeared to dominate the observed emission. The emission measurements showed marked differences between the ashes of the six coals tested, but no good correlation was observed between emission measurements and ash chemistry.

McCollor, D.P.; Zygarlicke, C.J. Subtask 3.2 - Characterization and Prediction of Ash Emissivity; Final Report (July 1, 1998 - Aug 31, 1999) for U.S. Department of Energy Cooperative Agreement No. DE-FC26-98FT40320; Energy \& Environmental Research Center: Grand Forks, ND, Dec 1999.

\section{Subtask 3.3 - High-Temperature Heat Exchanger Testing in a Pilot-Scale Slagging Furnace System}

A dynamic slag application furnace (DSAF) was designed and constructed to test refractories and alloys under realistic slag flow conditions in the laboratory. Measurements of corrosion by flowing slag on two oxide dispersion-strengthened (ODS) alloys, a nickel-chrome alloy and an iron-chrome-aluminum alloy, at tube surface temperatures of $1000^{\circ}, 1100^{\circ}, 1200^{\circ} \mathrm{C}$ and a slag temperature of $1500^{\circ} \mathrm{C}$ predicted excellent corrosion resistance if these alloy tubes were directly exposed to products of coal combustion in the high-temperature heat exchanger (HTHX) designed and built at the EERC in partnership with the United Technologies Research Center (UTRC) to advance the development of an indirectly fired combined-cycle power system operating on hot compressed air as the gas turbine working fluid. The results of laboratory corrosion tests in the DSAF formed the basis for the successful modification of the HTHX, involving removal of the ceramic panels initially used to protect alloy tubes from slag corrosion. Additives were also tested to control the viscosity of the slag for the purpose of maintaining a suitably thin layer of frozen slag on the hot metal tube to protect the surface from corrosion while maintaining high rates of heat transfer. Measurements indicated that ash deposits reduced heat transfer in the HTHX by about $20 \%$, compared to $50 \%$ commonly experienced in heat exchangers operating at lower temperatures. Improved methods were investigated for joining ODS alloys by transient liquid-phase bonding to preserve the oxide-dispersion microstructure of the joints.

Henderson, A.K.; Hurley, J.P.; Weber, G.F.; Hajicek, D.R.; Dockter, B.A.; Collings, M.E.; Kleven, P.L. Subtask 3.3 - High-Temperature Heat Exchanger Testing in a Pilot-Scale 
Slagging Furnace System; Final Report for U.S. Department of Energy Cooperative Agreement No. DE-FC26-98FT40320; Energy \& Environmental Research Center: Grand Forks, ND, Dec 1999.

\section{Subtask 3.4 - Impacts of Cofiring Biomass with Fossil Fuels}

Impacts of cofiring biomass with coal were investigated by characterizing the inorganic contents in biomass using advanced analytical methods, including wet chemical fractionation to determine exchangeable cations and CCSEM to analyze discrete mineral contents. Combustion tests were performed in the EERC's conversion and environmental process simulator (CEPS). Distinctive properties of biomass include silica-rich phytoliths and relatively high concentrations of potassium, phosphorus, and chlorine. Cofiring tests indicated good carbon burnout, harder slag and weaker ash-fouling deposits, a larger fraction of submicron particulate formed by condensation of volatile alkali compounds, and a higher potential for blinding SCR catalysts compared to firing most coals alone.

McCollor, D.P.; Zygarlicke, C.J.; Crocker, C.R.; Dahl, J.; Eylands, K.E.; Laducer, S.; Musich, M.A.; Hetland, M.D. Subtask 3.4 - Impacts of Cofiring Biomass with Fossil Fuels; Final Report (Apr 1, 1999 - Mar 31, 2001) for U.S. Department of Energy Cooperative Agreement No. DE-FC26-98FT40320; Energy \& Environmental Research Center: Grand Forks, ND, Aug 2001.

\section{Subtask 3.5 - Gasification for Distributed Generation}

The gasification properties of cultivated willow, alfalfa pellets, and black liquor from the Kraft wood pulping process were investigated to assess their suitability as fuel for distributed power generation. Results of preliminary tests performed using a thermogravimetric analyzer (TGA) indicated that the black liquor and the alfalfa pellets were more reactive and were gasified at lower temperatures (e.g., $700^{\circ} \mathrm{C}$ ) than willow (gasified above $800^{\circ} \mathrm{C}$ ). Subsequent tests were carried out in an integrated bench-scale fluidized-bed gasifier (IBG). Recovery of the sodium contained in black liquor was essential to the economics of the Kraft pulping process. Gasifying black liquor at $650^{\circ} \mathrm{C}$, which was possible because of the catalytic effect of sodium, resulted in quantitative recovery of sodium, whereas gasification at $800^{\circ} \mathrm{C}$ reduced sodium ions to elemental sodium that was vaporized out of the reactor. These results show that the gasification of black liquor is an effective means of disposing of black liquor while recovering sodium and producing a fuel gas with a high concentration of $\mathrm{H}_{2}$.

Schmidt, D.D.; Mann, M.D.; Timpe, R.C. Subtask 3.5 - Gasification for Distributed Generation;

Final Report (May 1, 1999 - Mar 31, 2000) for U.S. Department of Energy Cooperative Agreement No. DE-FC26-98FT40320; EERC Publication 2000-EERC-05-01; Energy \& Environmental Research Center: Grand Forks, ND, May 2000.

\section{Subtask 3.6 - Advanced Power System Analysis Tools}

The EERC has, over time, developed a compendium of analytical and modeling tools for characterizing fuels and fuel ash to predict fuel quality impacts in conventional and advanced 
power system performance. Specialized analytical tools developed at the EERC include CCSEM giving particle-by-particle analysis; chemical fractionation to distinguish exchangeable ions, soluble salts, and insoluble minerals; and SEM point count (SEMPC) to differentiate mineral interactions in deposits from chemical composition. Modeling tools have been developed for predicting ash formation, deposition on heat-transfer surfaces, slag flow, and plugging of hot-gas filters. Specialized models for predicting impacts in combustion systems include PCQUEST (predicts the impacts of ash on nine regions of conventional boiler), LEADER (predicts ash deposition in low-temperature regions of a boiler), CABRE II (predicts ash deposition in an entrained-flow gasifier), Fuel Quality Advisor (dynamic model that predicts ash deposition impacts on heat transfer), ATRAN (fly ash particle size and composition distribution), and Tracetran (trace element emissions in gasification systems). Advances made under this subtask include a new CCSEM technique providing far more detailed and accurate data and a new technique for characterizing deposits using gray-scale levels to distinguish different mineral phases.

Benson, S.A.; Jensen, R.R.; Laumb, J.D. Subtask 3.6 - Advanced Power System Analysis Tools; Final Report for U.S. Department of Energy Cooperative Agreement No. DE-FC2698FT40320; EERC Publication 2001-EERC-08-05; Energy \& Environmental Research Center: Grand Forks, ND, May 2005.

\section{Subtask 3.7 - High-Temperature Heat Exchange Development and Testing}

An engineering study was performed on the pilot-scale slagging furnace system (SFS) and the HTHX designed and built at the EERC in partnership with UTRC to support the development of an indirectly fired combined-cycle (IFCC) operating on hot compressed air as the gas turbine working fluid. Indirect firing greatly simplifies a coal-fired combined cycle system, and it eliminates the need for hot-gas filtration needed in integrated gasification combined-cycle (IGCC) systems. The HTHX was designed to heat air to temperatures up to $2000^{\circ} \mathrm{F}\left(1093^{\circ} \mathrm{C}\right)$ at a pressure of 250 psi (17 bar). Work performed under this subtask included 1) systems analyses to evaluate the HTHX for use in coal-fired power systems and industrial applications; 2) corrosion tests to evaluate HTHX alloys exposed to flowing slag, 3) tests on joining methods for ODS alloys, and 4) modification and testing of improvements to the SFS/HTHX system.

- Systems analyses showed the cost of electricity from a coal-fired IFCC power system would be competitive with either a modern pc-fired steam electric plant or an IGCC plant.

- Two ODS alloys were tested for use in the HTHX. MA754 is a chromia-scale forming nickel-chromium alloy; MA956 is an alumina-scale forming iron-chromium-aluminum alloy. Laboratory corrosion tests demonstrated that slag corrosion on both of these alloys can be controlled by operating at a surface temperature below the solidus temperature of the slag. However, temperature cycling caused the MA754 alloy to lose its slag coating along with a small amount of its protective chromia layer, which would be expected to reduce the useful life of this alloy in cycling service. The slag coating remained attached to the MA956 alloy after temperature cycling, indicating that this alloy would be more suitable in cycling applications. 
- Two methods were demonstrated for joining the ODS alloys used to make the HTHX, which, because of the oxide dispersion, cannot be welded. Mechanical joining proved to be very successful in the pilot-scale design, but transient liquid phase (TLP) joining would be a less expensive method for a commercial unit. Tests on a large matrix of TLP alloys and alloy application methods successfully produced joints exhibiting low porosity and good alloy diffusion (bonding).

- The HTHX was modified by removing the ceramic panels installed to protect the ODS alloy tubes in the original design. Air-blown tests after this modification showed no significant operational problems with either the slagging furnace or the bare tubes in the HTHX. Tube corrosion was not significant as long as the surface temperature of the HTHX was kept below the solidus temperature of the slag. Heat transfer in the HTHX was increased by a factor of 5 after the ceramic panels were removed. With the reduced size and elimination of ceramic panels factored in, the cost of the HTHX was estimated to be reduced by a factor of 10 .

- The last test on the slagging furnace and bare-tube HTHX was run using oxygen-enriched recycled flue gas in place of air. The oxygen-enriched test demonstrated still higher heattransfer rates in the HTHX at similar gas temperatures because of the very strong infrared radiation emitted by the $\mathrm{CO}_{2}$ and water vapor in the flue gas. Flue gas flow rates were reduced relative to air-blown operation, allowing for a reduction in the size of the furnace and pollution control devices in a commercial unit. Condensation of the water vapor in the flue gas would leave a concentrated stream of $\mathrm{CO}_{2}$ for sequestration.

Weber, G.F.; Bornstein, N.S.; Robson, F.L.; Collings, M.E.; Hurley, J.P.; Henderson, A.K. Subtask 3.7 - High-Temperature Heat Exchange Development and Testing; Final Topical Report (Nov 1, 2000 - Aug 31, 2004) for U.S. Department of Energy Cooperative Agreement No. DE-FC26-98FT40320; Energy \& Environmental Research Center: Grand Forks, ND, Aug 2004.

\section{Subtask 3.8 - Advanced Power System Studies}

Five activities were completed under this subtask:

- Research was performed to improve a key technique for characterizing fuel and ash properties by endeavoring to increase the number of mineral particles that can be classified by CCSEM tenfold by calibrating the gray scale from BSE images of mineral phases with known compositions. Existing CCSEM systems are effectively restricted to examining ca. 3000 mineral grains per sample because of the time-consuming x-ray acquisition process. The desired improvement was not attainable with current technology.

- Candidate sorbent compounds were investigated for capturing mercury from a reducing environment in a gasification system. Solid $\mathrm{HgS}$ and $\mathrm{HgSe}$ are stable in a reducing environment, and conversion of elemental mercury to these or other solid compounds would allow mercury particulate to be removed in a hot-gas filter. Several promising sorbents were identified, and patent disclosures are pending. 
- Real-time infrared (IR) thermography was evaluated as a thermal imaging technique for measuring surface temperatures and thermal gradients that reflect heat and mass flows. This technique was shown to be a very useful diagnostic tool when tested on pilot-scale combustion systems. Real-time thermal imaging can be used to improve the design and operation of full-scale power systems by identifying temperature excursions caused by ash deposition, abnormal flow patterns, material failures, or blockages.

- Research on the photoreaction of $\mathrm{TiO}_{2}$ for catalytically reducing $\mathrm{NO}_{\mathrm{x}}$ in flue gas from combustions systems showed that $\mathrm{NO}_{2}$ introduced into a dry air stream was removed by reaction and adsorption on $\mathrm{TiO}_{2}$. The $\mathrm{HNO}_{3}$ formed was removed by rinsing with water. However, when the gas temperature was increased and moisture was introduced, the amount of $\mathrm{NO}_{2}$ removed was greatly reduced. This technique was, therefore, not practical for controlling $\mathrm{NO}_{\mathrm{x}}$ in a combustion system.

- A vegetable-based coating applied to filter bags used for particulate control was shown to improve the removal of the residual filter cake during pulse-jet cleaning, thereby reducing baghouse pressure drop and improving plant efficiency. The use of this approach would also increase the service life of filter bags, and permit smaller baghouse units and fans to be utilized.

Yan, L.; Almlie, J.C.; Folkedahl, B.C.; Jensen, M.D.; Miller, S.J.; Williams, K.D.; Olson, E.S. Subtask 3.8 - Advanced Power System Studies; Final Report (Apr 1, 2001 - Sept 30, 2004) for U.S. Department of Energy Cooperative Agreement No. DE-FC26-98FT40320; EERC Publication 2004-EERC-12-04; Energy \& Environmental Research Center: Grand Forks, ND, Dec 2004.

\section{Subtask 3.9 - High-Speed Computing for Computational Fluid Dynamics Modeling with Validation Using Thermal Imaging}

Deposit growth was predicted using an integration of three coal ash models. Infrared thermography was also used as a method to monitor deposit growth in a coal-fired boiler in real time. Fouling of heat-transfer surfaces in boilers reduces efficiency and increases downstream pluggage, and methods for predicting or monitoring deposits would permit more effective operation of these systems. Testing was conducted in a pilot-scale combustor. An IR camera was used to monitor a probe inserted in the combustor's convective pass, with a digital image taken every minute for $1 \mathrm{hr}$. The images were used to determine deposit thickness. Temperatures were provided by the IR camera based on emissivity estimate. ATRAN, FLUENT, and FOULER models were integrated. Operating conditions were input into the integrated model, and a prediction of deposit growth rate was made. This prediction was compared with the deposit thickness measured by the IR camera. The deposit was measured to be 0.289 in. thick after $1 \mathrm{hr}$ of boiler operation. The integrated model predicted a deposit growth rate of $0.252 \mathrm{in} . / \mathrm{hr}$. This study showed that the integrated model can accurately predict deposit growth rates in a coal-fired boiler and infrared thermography can be effectively used to monitor deposit growth in real time.

Jensen, R.R.; Rokanuzzaman, A.S.; Kay, J.P. Subtask 3.9 - High-Speed Computing for Computational Fluid Dynamics Modeling with Validation Using Thermal Imaging; Final 
Report (Feb 14, 2003 - Jan 31, 2005) for U.S. Department of Energy Cooperative Agreement No. DE-FC26-98FT40320; EERC Publication 2005-EERC-03-03; Energy \& Environmental Research Center: Grand Forks, ND, Mar 2003.

\section{Subtask 3.10 - Power Production from Sour Gas}

Field tests validated long-term operation of a $30-\mathrm{kW}$ microturbine on sour gas $(1 \%-1.5 \%$ sulfur) from oil production. The sour gas is typically flared. The project provided verification of key performance metrics, including financial, emissions, and maintenance. Installation of a microturbine can achieve a 3.5-year simple payback based on electricity savings and maintenance costs. The microturbine achieved an $84 \%$ annual availability, producing $28 \mathrm{~kW}$ of power on average over 7971 hours of operation. Emissions of $\mathrm{NO}_{\mathrm{x}}, \mathrm{CO}, \mathrm{VOC}$, and $\mathrm{SO}_{2}$ were measured and compared to flare operation. The respective reductions are $54.9 \%, 62.4 \%, 98.2 \%$, and $89.7 \%$. The fuel system maintenance included a compressor top-end rebuild that did not appear to be caused by corrosion and fuel nozzle fouling. The fuel nozzle fouling revealed that replacement of nozzles is prudent on an annual basis. The microturbine and gas compression system withstood over 7000 hours of relatively continuous operation. Grid-related faults were the primary cause for shutdown.

Schmidt, D.D. Subtask 3.10 - Power Production from Sour Gas; Final Report (Apr 1, 2003 June 30, 2006) for U.S. Department of Energy Cooperative Agreement No. DE-FC2698FT40320; EERC Publication 06-EERC-06-01; Energy \& Environmental Research Center: Grand Forks, ND, Jun 2006.

\section{Subtask 3.11 - FutureGen Technologies}

Research was performed on four topics to advance the development of FutureGen technologies that will use fossil and alternative fuels with near-zero emissions: 1) coal combustion in an oxygen-water vapor $\left(\mathrm{O}_{2}-\mathrm{H}_{2} \mathrm{O}\right)$ atmosphere, 2) a feeding system that utilizes a carbon dioxide $\left(\mathrm{CO}_{2}\right)$ coal slurry to feed high-moisture low-rank coal into high-pressure conversion processes, 3) pilot-scale testing of a hydrogen production process integrating fluidized-bed gasification with steam reforming; and 4) the use of alloy hydrides for hydrogen storage.

- TGA tests performed in an $\mathrm{O}_{2}-\mathrm{H}_{2} \mathrm{O}$ atmosphere indicated reductions in $\mathrm{NO}_{\mathrm{x}}$ and $\mathrm{CO}$ formation compared to tests performed in air and production of up to $1000 \mathrm{ppm}_{2}$ because of partial gasification in the $\mathrm{O}_{2}-\mathrm{H}_{2} \mathrm{O}$ atmosphere. Carbon conversions of nearly $100 \%$ were obtained in tests performed in a bench-scale drop-tube furnace (DTF) in an $\mathrm{O}_{2}-\mathrm{H}_{2} \mathrm{O}$ vapor atmosphere. Comparisons of fly ash size and chemistry revealed no substantial differences between combustion in air and in an $\mathrm{O}_{2}-\mathrm{H}_{2} \mathrm{O}$ vapor atmosphere.

- Viscosities of coal-liquid $\mathrm{CO}_{2}$ slurries were measured as a function of coal moisture content, particle size, solids loading, and fuel type to evaluate the feasibility of using a carbon dioxide slurry feed system to reduce the energy penalty experienced when high-moisture coal is fed into an entrained-flow gasifier as a coal-water slurry. Viscosities ranged from ca. 100 to 
$250 \mathrm{cP}$, which were an order of magnitude higher than viscosities reported by others for lignite- $-\mathrm{CO}_{2}$ slurries at solids concentrations above $80 \mathrm{wt} \%$.

- Sulfur-tolerant water-gas shift catalysts were screened by TGA, differential scanning calorimetry (DSC), and FT-IR and subsequently integrated with a laboratory-scale fluidizedbed gasifier to assess potential for increasing hydrogen yield and reducing the heat requirement of the gasifier. The TGA analysis showed that catalyst sulfidation occurred between $150^{\circ}$ and $300^{\circ} \mathrm{C}$ and that water-gas shift conversion occurred in the same temperature range. Gasifier tests on coal spiked with elemental sulfur indicated that only minor changes in $\mathrm{H}_{2}, \mathrm{CO}$, and $\mathrm{CO}_{2}$ occurred in the catalyst reactor at temperatures of $230^{\circ}$, $270^{\circ}$, and $295^{\circ} \mathrm{C}$. Shift conversion was limited by catalyst deactivation.

- Experiments were performed to develop magnesium alloy hydrides with lower heats of formation and high surface areas so that they will decompose at $125^{\circ} \mathrm{C}$ and undergo rapid regeneration. Intermediate magnesium and alloy carbides were prepared for use as reactants to form magnesium hydride. GC results showed that magnesium carbide intermediates could be hydrogenated to give propane, propene, and a magnesium hydride/carbide; however, the yields were small. The results also indicated that hydrogen was not able to penetrate the carbide structures as completely as hoped. Alternatively, a tetrahydrofuran-soluble magnesium adduct of anthracene was impregnated into a porous carbon and converted to the carbon-supported magnesium hydride by heating under hydrogen and to carbon-supported magnesium metal by heating under nitrogen to release the anthracene. The magnesium-based sorbent, which adsorbed and released $7.6 \mathrm{wt} \% \mathrm{H}_{2}$, was superior to a commercial nickel-based sorbent on a hydrogen-weight, sorbent weight basis.

McCollor, D.P.; Swanson, M.L.; Timpe, R.C.; Zygarlicke, C.J. Subtask 3.11 - FutureGen Technologies; Final Technical Report (Feb 26, 2004 - Dec 31, 2005) for U.S. Department of Energy Cooperative Agreement No. DE-FC26-98FT40320; EERC Publication 2006-EERC05-02; Energy \& Environmental Research Center: Grand Forks, ND, May 2006.

\section{Subtask 3.12 - Oxygen-Fired CFBC}

An engineering design study was completed to determine the feasibility of modifying the existing 1-MWth pilot-scale circulating fluidized-bed combustor (CFBC) at the EERC to oxygenblown operation. The advantages of an oxygen-fired system are that it would increase fuel throughput and efficiency by improving heat transfer and, most importantly, produce a concentrated steam of $\mathrm{CO}_{2}$ suitable for sequestration. The study addressed the control of bed temperature in relation to flue gas and solids recycle and staging of oxygen and recycled flue gas. Staging has the added benefit of potentially decreasing emissions of nitrogen oxides. The study shows that modifications could be accomplished using, primarily, components already available at the EERC, including the oxygen flow and control system used on the transport reactor development unit (TRDU) gasifier. Additions would include the fan required for flue gas circulation and upgrades in the measurement and control of coal and limestone feed and gas flow. 
Hajicek, D.R.; Musich, M.A.; Henderson, A.K. Subtask 3.12 - Oxygen-Fired CFBC; Final Report (Apr 1, 2005 - Feb 28, 2007) for U.S. Department of Energy Cooperative Agreement No. DE-FC26-98FT40320; EERC Publication 2007-EERC-05-13; Energy \& Environmental Research Center: Grand Forks, ND, Mar 2007.

\section{Subtask 3.13 - Enhanced Hydrogen Production from Water-Gas Shift}

Water-gas shift catalysts can be utilized to enhance hydrogen production; however, equilibrium considerations limit the amount of hydrogen produced. If $\mathrm{CO}_{2}$ removal were integrated with the water-gas shift reaction, hydrogen production would be enhanced. Laboratory TGA experiments were performed to evaluate sorbents that could be used in gasification systems to enhance the water-gas shift reaction by absorbing the $\mathrm{CO}_{2}$ produced. Tests performed on magnesium-alumina hydroxy carbonates (hydrotalcites with $20 \% \mathrm{~K}_{2} \mathrm{CO}_{3}$ added as a promoter) at $400^{\circ} \mathrm{C}$ measured cyclic absorption of $\mathrm{CO}_{2}$ from both $100 \% \mathrm{CO}_{2}$ and a $20 \% \mathrm{CO}_{2} / 80 \% \mathrm{~N}_{2}$ gas mixture and subsequent desorption into $100 \% \mathrm{~N}_{2}$ sweep gas. The highest absorption capacity of $1.7 \% \mathrm{wt} \% \mathrm{CO}_{2}$ was observed for a Sasol MG70 hydrotalcite. The level of desorption was between $85 \%$ and $90 \%$ in the first cycle but declined in succeeding cycles. Substantially higher absorption capacities of about $15 \mathrm{wt} \% \mathrm{CO}_{2}$ were observed for lithium silicate between $500^{\circ}$ and $600^{\circ} \mathrm{C}$, with capacity increasing only marginally at higher gas concentrations between $20 \%$ and $100 \% \mathrm{CO}_{2}$ in nitrogen. Desorption from lithium silicate was $90 \%$ using $100 \% \mathrm{~N}_{2}$ sweep gas at $600^{\circ} \mathrm{C}$.

Swanson, M.L. Subtask 3.13 - Enhanced Hydrogen Production from Water-Gas Shift; Draft Final Report (Apr 1, 2005 - Mar 31, 2009) for U.S. Department of Energy Cooperative Agreement No. DE-FC26-98FT40320; Energy \& Environmental Research Center: Grand Forks, ND, May 2007.

\section{Subtask 3.14 - Advanced Characterization of Slags and Refractory Bricks Using Electron Backscatter Diffraction}

New capabilities were developed for examining the chemical and crystalline structure of slags and refractories in the submicron range to advance knowledge of slag corrosion and phase behavior in high-temperature environments. A new EBSD system installed on an existing SEM has been shown to identify crystalline phases as small as $0.5 \mu \mathrm{m}$. Exploratory studies using EBSD to examine iron-rich slags identified submicron dendritic crystals that precipitated from the amorphous silicate, which changed depending on time and temperature. This information, which could not be obtained from the SEM analysis alone, will provide new insight into the relationship of slag viscosity and temperature and particularly the temperature of critical viscosity below which crystallization controls the increase in viscosity. The information is also very important in understanding the mechanisms of slag corrosion from the standpoint of slag fluidity and the incursion of dendritic crystals that breach the surface integrity of refractory surfaces and tube scale. Slag viscosity and corrosion are critical properties affecting hightemperature components of gasifiers, heat exchangers, and other energy conversion equipment.

Eylands, K.E.; Kay, J.P. Subtask 3.14 - Advanced Characterization of Slags and Refractory Bricks Using Electron Backscatter Diffraction; Final Report (Mar 1, 2006 - Sept 30, 2007) 
for U.S. Department of Energy Cooperative Agreement No. DE-FC26-98FT40320; EERC Publication 2007-EERC-09-07; Energy \& Environmental Research Center: Grand Forks, ND, Sept 2007.

\section{Subtask 3.15 - Hydrogen Production from High-Temperature Sources}

High temperatures available in nuclear reactors and solar collectors can effect the splitting of water to form hydrogen without concomitant production of $\mathrm{CO}_{2}$. The remaining oxide is subsequently decomposed to oxygen at a higher temperature in a second stage of the cycle. This subtask investigated the use of high-porosity and high-surface-area ferrites for thermally splitting water, with the objective of obtaining high yields of hydrogen. Several nickel and manganese ferrites were prepared by heating in argon at $1000^{\circ} \mathrm{C}$ to convert them to the oxygen-deficient material and then tested by passing an argon-steam mixture through the heated sample in a tube reactor at $700^{\circ} \mathrm{C}$. The resulting hydrogen yields of 0.1 to $0.3 \mathrm{mg} / \mathrm{g}$ of ferrite represented only $1 \%-3 \%$ of the theoretical yields based on complete conversion of the ferrite to the oxygendeficient form and subsequent complete reaction with water. High surface area nanoparticle ferrites, including $\mathrm{Fe}_{2} \mathrm{O}_{3}$, (MnZn) $\mathrm{Fe}_{2} \mathrm{O}_{4}$, (NiZn) $\mathrm{Fe}_{2} \mathrm{O}_{4}$, and surface-coated $\mathrm{Fe}_{2} \mathrm{O}_{3}$ prepared by impregnation of $\mathrm{Ni}$ and $\mathrm{Mn}$ salts, were activated at $1000^{\circ} \mathrm{C}$ and reacted with steam. None of these materials promoted reaction to form hydrogen. Next, a Ni-Mn ferrite was reduced with hydrogen and then reacted with $\mathrm{CO}_{2}$ to deposit carbon on the surface; this material gave much higher yields of hydrogen (over $20 \%$ of theoretical) when reacted with steam, but its thermal regeneration was unsuccessful. The oxygen-deficient ferrites utilized in this project were either not prepared by heating to a sufficiently high temperature, or the steam reaction was not conducted at sufficient temperature. Higher temperatures are in fact available, especially in a solar furnace, and the reactions investigated here need to be further studied at higher temperatures.

Olson, E.S. Subtask 3.15 - Hydrogen Production from High-Temperature Sources; Final Report (Jan 1, 2005 - Mar 31, 2008) for U.S. Department of Energy Cooperative Agreement No. DE-FC26-98FT40320; EERC Publication 2008-EERC-06-09; Energy \& Environmental Research Center: Grand Forks, ND, June 2008.

\section{Subtask 3.16 - Low-Btu Oil Field Gas Application to Microturbines}

Low-Btu gas from oil production often does not meet the manufacturer's lower limit of gas heating value of $350 \mathrm{Btu} / \mathrm{scf}$ set for a microturbine, and this gas is typically flared. In this subtask, a C30 Capstone microturbine was modified at the EERC and successfully operated firing gases between 100-300 Btu/scf. Information on ignition and stable operation, $\mathrm{NO}_{\mathrm{x}}$ emissions, and power derating on low-Btu gas was obtained to provide the technical basis for developing these resources for distributed power generation. The microturbine operated at full power firing gas with a heating value as low as $200 \mathrm{Btu} / \mathrm{scf}$. A power derating was experienced firing gases below $200 \mathrm{Btu} / \mathrm{scf}$. As fuel energy content decreased, $\mathrm{NO}_{\mathrm{x}}$ emissions decreased, $\mathrm{CO}$ emissions increased, and unburned hydrocarbons remained below $0.2 \mathrm{ppm}$. A catalytic converter can be used to reduce $\mathrm{CO}$ for sites where $\mathrm{CO}$ emissions are a concern. The turbine achieved selfignition on $200 \mathrm{Btu} / \mathrm{scf}$ gas. A start-up fuel can be used to provide ignition before the system switches to low-Btu gas. 
Schmidt, D.D. Subtask 3.16 - Low-Btu Oil Field Gas Application to Microturbines; Final Report (Apr 1, 2006, - June 30, 2007) for U.S. Department of Energy Cooperative Agreement No. DE-FC26-98FT40320; EERC Publication 2007-EERC-05-08; Energy \& Environmental Research Center: Grand Forks, ND, May 2007.

\section{TASK 4.0 - ADVANCED FUEL FORMS}

\section{Subtask 4.1 - Conversion of Lignocellulosic Materials to Chemicals and Fuels}

The reaction of lignocellulose with alcohol was investigated to produce levulinate and formate esters. A significant part of the cellulose was carbonized to a charcoal. Subsequent reaction of ethyl levulinate with phenol produced resin intermediates analogous to diphenolic acid used in the production of epoxy resins, polyurethanes, polyamines, and polycarbonates. Other resinous materials were produced by adding amines to the ethyl levulinate. Epoxy resins produced from lignocellulose wastes provided high bonding strengths comparable to commercial epoxy resins. The cost of producing resins from lignocellulose is expected to be low compared to production from diphenolic acid, and commercial applications are being pursued.

Olson, E.S. Subtask 4.1 - Conversion of Lignocellulosic Material to Chemicals and Fuels; Final Report (Apr 1, 2000 - June 30, 2001) for U.S. Department of Energy Cooperative Agreement No. DE-FC26-98FT40320; EERC Publication 2001-EERC-06-09; Energy \& Environmental Research Center: Grand Forks, ND, June 2001.

\section{Subtask 4.2 - Low-Intensity Treatment of Low-Rank Coals, Lignin Waste, and/or Other Biomass to Obtain Liquid Fuel and Products of Added Value}

Under previous Cooperative Agreements and other DOE-sponsored research, the EERC developed and patented a four-step, low-intensity direct liquefaction process specifically for lowrank coals (LRCs). The process, which consists of pretreatment, solubilization, polishing, and hydrotreatment steps, was designed to take advantage of the high reactivity levels of the LRCs without experiencing excessive coking. Conversions of over $80 \%$ of the moisture- and ash-free (maf) coal to the tetrahydrofuran (THF)-soluble liquids were achieved in the pretreatment and solubilization steps (additional conversion and upgrading occurred in the polishing and hydrotreatment steps). Tests under this subtask were run to determine if the multistep process would work equally well for coprocessing coal with the addition of other carbon sources such as waste tires, municipal solid waste (MSW), peat, waste oils/solvents, and biomass. Similar tests were run in cresylic acid under low-intensity conditions on 1) hybrid poplar and 2) a 50:50 mixture of lignite:hybrid poplar. Reaction conditions were $115^{\circ} \mathrm{C}$ and 9.5 atmospheres (1400 psig) for pretreatment, followed by $350^{\circ} \mathrm{C}$ and 21.8 atmospheres $(3200$ psig) for solubilization with $\mathrm{H}_{2} \mathrm{~S}$ catalysis. Carbon conversions were ca. $98 \%$ for both the biomass and biomass-coal as determined by THF solubility. The coal-poplar product had the appearance of automotive motor oil. The poplar product was very dark in color. Both products were mixtures of aliphatic and aromatic organic hydrocarbons and of hydrocarbons containing oxygen, nitrogen, and sulfur heteroatoms. 
Timpe, R.C. Subtask 4.2 - Low-Intensity Treatment of Low-Rank Coals, Lignin Waste, and/or Other Biomass to Obtain Liquid Fuel and Products of Added Value; Final Report (Apr 1, 2000 - June 30, 2001) for U.S. Department of Energy Cooperative Agreement No. DEFC26-98FT40320; EERC Publication 2001-EERC-06-02; Energy \& Environmental Research Center: Grand Forks, ND, June 2001.

\section{Subtask 4.3 - Removal of Sulfur from Diesel Fuel with Subcritical Water}

Research was performed to develop a low-cost alternative to catalytic hydrogenation for reducing sulfur in diesel fuel. The predominant sulfur-containing compounds in diesel fuel are aromatic sulfur-containing organics such as benzothiophene and related compounds. The solubilities of sulfur-containing organics were demonstrated to increase by ca. 15,000-fold when water was heated from ambient to $250^{\circ} \mathrm{C}$, indicating that stripping of these compounds from the diesel fuel could be accomplished in water at the higher temperatures. Dynamic (flowing) extractions of diesel fuel at water temperature ranging from $100^{\circ}$ to $250^{\circ} \mathrm{C}$ confirmed the ability of subcritical water to remove the S-organics and PAHs from diesel fuel using very large volumes of water. A static extraction was performed to determine the minimum ratio of water to diesel fuel that would result in substantial removal of S-organics. The static test confirmed the ability to remove S-organics at higher water temperatures, but only with very high (e.g., $>100$ to 1) ratios of water to diesel fuel. The results demonstrated that subcritical water (hot water at sufficient pressure to maintain the liquid state) can be used to remove sulfur-containing organic compounds as well as undesirable PAHs from diesel fuel, while not removing any detectable amount of the desired aliphatic hydrocarbons in the fuel. However, the ratio of water to treated diesel fuel required is very high.

Hawthorne, S.B. Subtask 4.3 - Removal of Sulfur from Diesel Fuel with Subcritical Water; Final Report (Apr 1, 2004 - Mar 31, 2005) for U.S. Department of Energy Cooperative Agreement No. DE-FC26-98FT40320; EERC Publication 2005-EERC-06-11; Energy \& Environmental Research Center: Grand Forks, ND, June 2005.

\section{Subtask 4.4 - North Dakota Lignite Fuel Upgrading}

This subtask established an added capability at the EERC for testing Fischer-Tropsch (FT) catalysts in a bench-scale continuous fluid-bed reactor that could be attached to the EERC's gasification reactors. This capability will allow catalyst vendors to test catalysts on actual coalderived syngas and will also allow the EERC to develop new expertise in this area. A study performed for the EERC by Dr. Calvin Bartholomew at Brigham Young University (BYU) recommended that it would be possible to build a single reactor (rather than multiple reactors of different sizes) consisting of three 1-inch-diameter, 10-foot-long tubes to accommodate the anticipated range of catalytic activities and process conditions. The recommended reactor would be designed to operate over a significant range of recycle ratios (e.g., $1-10)$, temperatures $\left(25^{\circ}\right.$ $\left.400^{\circ} \mathrm{C}\right)$, pressures $(10-25 \mathrm{bar})$, flow rates $(1-6 \mathrm{scfm})$, and cooling duty $(0.2-1.5 \mathrm{~kW})-$ and it would provide flexibility for directing gas to one, two, or three tubes. Within the limits of the subtask budget, a two-bed reactor system was constructed with provision for adding a third reactor at a later time. This system was sized to fit on several of the EERC's gasification reactors, including the EERC's $4-\mathrm{lb} / \mathrm{hr}$ continuous fluid-bed gasification reactor, a slipstream 
from the pilot-scale TRDU, and gasification reactors in the high-bay area of the National Center for Hydrogen Technology building.

Swanson, M.L. Subtask 4.4 - North Dakota Lignite Fuel Upgrading; Final Report (Apr 1, 2006 Mar 31, 2009) for U.S. Department of Energy Cooperative Agreement No. DE-FC2698FT40320; EERC Publication 2009-EERC-06-07; Energy \& Environmental Research Center: Grand Forks, ND, April 2009.

\section{TASK 5.0 - VALUE-ADDED COPRODUCTS}

\section{Subtask 5.1 - Effects of Sodium and Calcium Content in Lignite on the Performance of Activated Carbon Products}

Tests were performed to determine the effects of organically and mineralogically associated sodium and calcium content on pore structure, pore-size distribution, and sorption capacity of activated carbon products. Three different coal samples were evaluated: high-sodium content, high-calcium content, and relatively low-sodium and low-calcium content. The coal samples were carbonized in a nitrogen atmosphere at $400^{\circ} \mathrm{C}$ and activated with steam at $700^{\circ} \mathrm{C}$ for 30 minutes. The resultant activated carbon samples were characterized for surface area and pore-size distribution and evaluated by performing sorption isotherms for a variety of solutes, including benzene, carbon tetrachloride, humates, metals, and biorefractory organics. Comparison of mercury sorption on different types of carbon indicated that the chemistry of the carbon surface is more important than surface area. Activated carbons derived from lignite generally exhibit superior sorption properties, with higher sodium content and, to a lesser degree, calcium content having a beneficial effect. However, no correlation between mercury capture and inorganic content was identified in tests where the inorganic content of a commercial Norit activated carbon was progressively removed by washing with a series of reagents.

Stepan, D.J.; Olson, E.S.; Eylands, K.E. Subtask 5.1 - Effects of Sodium and Calcium Content in Lignite on the Performance of Activated Carbon Products; Final Report (Apr 1, 2000 - Nov 30, 2001) for U.S. Department of Energy Cooperative Agreement No. DE-FC26-98FT40320; EERC Publication 2001-EERC-12-01; Energy \& Environmental Research Center: Grand Forks, ND, Dec 2001.

\section{Subtask 5.2 - Development of Carbon Fibers from Low-Rank Coals}

The goal of this subtask was to produce carbon fibers from low-rank coal tars. Tests were first carried out to improve the normally low yield of tar from LRCs by demineralizing samples of high-sodium and low-sodium North Dakota lignite by ion exchange with ammonium acetate and by cation dissolution with nitric acid. Pyrolysis of six sets of raw and demineralized samples all produced very small yields of $\operatorname{tar}<1 \mathrm{wt} \%$, and the yields of volatile soluble tars that would be used for pitch formation were actually decreased for the ion-exchanged coal. The pyrolysis tars from these samples had a very similar composition as determined by GC. As an alternative method for producing pitch, the set of six raw and demineralized coals were heated to ca. $400^{\circ} \mathrm{C}$ to convert the coals to the metaplast, which was extracted in tetralin. Much higher yields of 
tarlike material were obtained, compared with the yields of volatile tars obtained in the pyrolysis experiments. The tetralin and unwanted aliphatic waxy material were separated from the extracts by dissolving them in hexane. The hexane-insoluble portion represented the material that would be used to make pitch. In these experiments, the yields of hexane-insoluble metaplast increased significantly as a result of demineralization of both the high-sodium and low-sodium coals. Also, this material had a higher melting temperature than the tar fractions obtained by pyrolysis, making it more suitable for conversion to pitch and subsequently to fibers.

Olson, E.S. Subtask 5.2 - Development of Carbon Fibers from Low-Rank Coals; Final Report for U.S. Department of Energy Cooperative Agreement No. DE-FC26-98FT40320; EERC Publication 2001-EERC-07-02; Energy \& Environmental Research Center: Grand Forks, ND, July 2001.

\section{Subtask 5.3 - Installation of a Bench-Scale Rotary Kiln Reactor}

This subtask enhanced the capabilities of the EERC to produce and test sorbents for mercury by installing and testing a bench-scale rotary kiln capable of producing several kilograms per hour of activated carbon. The economics of activated carbon injection for the control of mercury emissions from coal-fired plants depends on achieving adequate control at low carbon injection rates. Previous laboratory experiments producing gram quantities of activated carbon showed that carbons produced from high-sodium lignite exhibited superior sorption of mercury. Production of larger amounts of these activated carbons for pilot-scale mercury control tests was facilitated by installation of the rotary kiln.

Benson, S.A.; Crocker, C.R.; Musich, M.A.; Mackenzie (Zola), J.M.; Olson, E.S. Subtask 5.3 Installation of a Bench-Scale Rotary Kiln Reactor; Final Report (Apr 1, 2003 - Apr 30, 2005) for U.S. Department of Energy Cooperative Agreement No. DE-FC26-98FT40320;

EERC Publication 2005-EERC-04-03; Energy \& Environmental Research Center: Grand Forks, ND, April 2005.

\section{TASK 6.0 - ADVANCED MATERIALS}

\section{Subtask 6.1 - Corrosion of High-Temperature Alloys}

The corrosion rates of different superheater tube alloys under conditions representing a USC boiler were determined after 1000 hours' exposure to ash in a flue gas atmosphere at $625^{\circ} \mathrm{C}$. For conditions simulating the cofiring of bituminous coal with high-potassium biomass, alloys which formed an iron oxide scale experienced much greater corrosion than highchromium alloys that formed a chromium oxide layer. In tests on high-chromium alloys, the addition of water vapor did not significantly affect the oxide layer or the corrosion rate, but the addition of hydrochloric acid vapor resulted in some breakdown of the chromium oxide layer and an increase in corrosion. In tests representing the firing of high-sodium lignite, ODS alloys, which contain traces of inert metal oxides to stabilize the grain structure at high temperatures, experienced less corrosion than high-chromium/high-nickel $(\mathrm{HCN})$ alloys. Contrary to the expectation of greater corrosion for high-sodium lignite, little corrosion was observed for either 
type of alloy. Overall, ODS alloys offered the best corrosion protection. HCN alloys provide marginally less protection and should be evaluated further in reference to ash composition and steam tube temperature.

Hurley, J.P.; Kay, J.P. Subtask 6.1 - Corrosion of High-Temperature Alloys; Final Topical Report for U.S. Department of Energy Cooperative Agreement No. DE-FC26-98FT40320; EERC Publication 99-EERC-10-04; Energy \& Environmental Research Center: Grand Forks, ND, October 1999.

\section{Subtask 6.2 - Hydrogen Separation Membranes}

Improved technologies are needed to separate $\mathrm{CO}_{2}$ and impurities including $\mathrm{H}_{2} \mathrm{~S}, \mathrm{NH}_{3}$, and trace metals from the coal-derived fuel gas to produce hydrogen for advanced gas turbines and fuel cells and to facilitate sequestering of $\mathrm{CO}_{2}$ at reduced cost. The objective of this subtask was to develop and test gas separation membranes capable of operating at the temperatures and atmospheres found in a gasification product stream. The results of a literature review suggested that a $\mathrm{ZnS}$ membrane would be a promising choice for high-temperature hydrogen separation, since the n-type semiconductor character is favorable for the chemisorption of hydrogen and $\mathrm{H}_{2}$ is known to diffuse into the analogous $\mathrm{ZnO}$. In addition, $\mathrm{ZnS}$ is resistant to $\mathrm{H}_{2} \mathrm{~S}$. The first $\mathrm{ZnS}$ membranes attempted were made by depositing $\mathrm{ZnS}$ on substrates using electron beam deposition. Failure of the high-voltage power supply of this instrument necessitated finding alternative means of depositing the $\mathrm{ZnS}$ coating. Attempts to deposit $\mathrm{ZnS}$ on a sintered stainless steel substrate either by thermal deposition in a carbon-coating instrument or by sublimation in a tube furnace failed to seal the porosity of the substrate against nitrogen. Chemical precipitation of $\mathrm{ZnS}$ on a sintered stainless steel substrate was subsequently investigated by alternately applying aqueous solutions of $\mathrm{Zn}\left(\mathrm{NO}_{3}\right)_{2}$ and $\mathrm{Na}, \mathrm{S}$ to the porous substrate. No satisfactory method was identified for preparing a usable $\mathrm{ZnS}$ membrane for testing.

Kay, J.P.; McCollor, D.P. Subtask 6.2 - Hydrogen Separation Membranes; Final Report (Apr 1, 1998 - Apr 30, 1999) for U.S. Department of Energy Cooperative Agreement No. DOE DEFC26-98FT40320; Energy \& Environmental Research Center: Grand Forks, ND, Aug 1999.

\section{Subtask 6.3 - Silicon Carbide Joining}

Methods were developed for reaction-bonding silicon carbide ( $\mathrm{SiC}$ ) to form joints for fabricating large structural ceramics for applications such as high-temperature ceramic heat exchangers and components for the metals and glass industries. In-place joining of $\mathrm{SiC}$ components is accomplished by passing an electric current through a joining paste made by coating $\mathrm{SiC}$ filler particles with Si metal and adding carbon in the form of a resin to react with the Si. Optimizing the paste formulations and heating conditions produced joints that were structurally sound to $1425^{\circ} \mathrm{C}$ by eliminating channels of silicon that melt above $1200^{\circ} \mathrm{C}$ and that achieved a significant reduction in porosity. Techniques investigated to reduce porosity and increase strength included 1) covering $\mathrm{SiC}$ particles with silicon metals to promote stronger reaction bonding; 2) using a flowable liquid organic polymer, polyacrylacetylene, that was profused into the joining compound and pyrolyzed in place to carbon; and 3) testing a commercially available polycarbosilane, Ceraset, which pyrolyzes to form amorphous SiC rather 
than carbon. The Ceraset reduced porosity down to approximately $35 \%$, which was still inadequate. Further improvement using Ceraset resin would require extremely high temperatures $\left(2100^{\circ} \mathrm{C}\right)$ and pressures to crystallize the amorphous $\mathrm{SiC}$ pyrolysis product.

Work was also performed on the use of reaction-bonded $\mathrm{SiC}$ to form cast composites for applications that could include high-temperature ceramic heat exchangers in advanced power systems, ballistic armor on military weapons systems, and corrosion-resistant components for the metals and glass industries. The material starts as a $\mathrm{Si}-\mathrm{SiC}$ slurry that can be cast in any shape and fired with less than $0.5 \%$ shrinkage. After the material is fired to bond the carbide, it is continuous but only $65 \%$ dense so that additional materials such as metals or polymers can be infiltrated into the structure, making it much more resistant to breaking. Three types of $101 \times$ $89 \times 10-\mathrm{mm}$ plates were prepared and shot with rifle bullets to test their ability to resist shattering. The first plate was made of sintered $\mathrm{Si}-\mathrm{SiC}$ without converting the $\mathrm{Si}$ to $\mathrm{SiC}$; the second consisted of sintered $\mathrm{Si}-\mathrm{SiC}$ into which a rapid-setting epoxy had been infiltrated; and the third was sintered $\mathrm{Si}-\mathrm{SiC}$ in which the $\mathrm{Si}$ had been partially converted to $\mathrm{SiC}$. All of the plates stopped the .22 caliber bullets from penetrating, but the two plates without epoxy shattered. Resistance to breakage was further improved by using a lower-viscosity thermoset epoxy to increase the penetration of the resin into pores.

Hurley, J.P.; Kay, J.P. Subtask 6.3 - Silicon Carbide Joining; Final Report (Apr 15, 1999 - Apr 30, 2001) for U.S. Department of Energy; EERC Publication 2001-EERC-06-04; Energy \& Environmental Research Center; Grand Forks, ND, June 2001.

\section{Subtask 6.4 - Refractory Corrosion in the Metals and Glass Industries}

New test facilities and methods have been developed at the EERC to accurately simulate the conditions leading to high-temperature corrosion of refractories in coal-fired power systems. Under this task, rare earth oxides were mixed with castable alumina refractories to determine if they would increase sintering and reduce corrosion by molten coal slags. Tests indicated that the rare earth oxides did not increase sintering of the refractories to improve strength. In addition, both laboratory- and bench-scale tests showed that no passive corrosion-reducing layer enriched in rare earth oxides was formed at the surface of the refractory. Based on pilot-scale evidence from the EERC's work on the Combustion 2000 program, the best approach for preventing slag corrosion of alumina castable refractories is to prevent slag penetration through the use of paintable coatings that melt at temperatures just above the normal use temperature and then react with the alumina to form a layer that has a much higher melting point than the initial coating.

Hurley, J.P.; Kleven, P.L. Subtask 6.4 - Refractory Corrosion in the Metals and Glass Industries; Final Report (Apr 15, 1998 - Apr 30, 1999) for U.S. Department of Energy Cooperative Agreement No. DE-FC26-98FT40320; Energy \& Environmental Research Center: Grand Forks, ND, Apr 1999.

\section{Subtask 6.5 - SiAION Coatings of Silicon Carbide and Silicon Nitride}

Corrosion-resistant ceramic coatings for turbine blades were investigated in collaboration with Ames Laboratory. Coatings were applied to silicon nitride and INCOLOY alloys either by 
plasma spraying of SiAlON-Y and $\mathrm{Y}_{2} \mathrm{SiO}_{5}$ powders or as gels compounded from nanoparticles of yttria and silica. SiAlON ceramics are good candidate coatings that offer corrosion resistance to alkalies because of the yttria-alumina-garnet (YAG) interface that forms during corrosion of SiAlON-Y ceramics in combustion gases at $1300^{\circ} \mathrm{C}$. The hypothesis for this work was that a difference in the coefficients of thermal expansion (CTEs) for the cubic and tetragonal phases in the crystallized YAG generates compressive stresses that stabilize the interface to provide durable corrosion protection. Since literature values of the CTEs were not found, it was necessary to synthesize $\mathrm{Al}_{5} \mathrm{Y}_{3} \mathrm{O}_{12}$ and measure the cubic and tetragonal thermal expansion coefficients. Aluminum yttrium oxide was synthesized from stoichiometric amounts of the constituent oxides calcined in an alumina crucible at $1600^{\circ} \mathrm{C}$ for $15 \mathrm{hr}$ in air. The CTEs for $\mathrm{Al}_{5} \mathrm{Y}_{3} \mathrm{O}_{12}$ were measured using a high-temperature Philips $\mathrm{X}^{\prime}$ Pert MPD x-ray diffractometer equipped with $\mathrm{Cu} \mathrm{K} \alpha$ radiation, in the temperature range of $20^{\circ}$ to $1400^{\circ} \mathrm{C}$. Analysis of thermal stresses and evaluation of their effect on the corrosion of SiAlON-Y suggests that the YAG precipitates generate an axial compressive stress within a small region at the SiAlON-Y-YAG interface. The compressive stress in the thin boundary layer reduces the flux of sodium ions into the bulk of SiAlON ceramic and simultaneously reduces the corrosion rate. The YAG layer is a thermodynamically stable phase and, therefore, offers corrosion protection. Work on this topic in the following year under Subtask 6.6 prepared dense well-bonded coatings of $\mathrm{Y}_{2} \mathrm{SiO}_{5}$ and small amounts of $\mathrm{Y}_{2} \mathrm{Si}_{2} \mathrm{O}_{7}$ on silicon nitride by reacting yttria and silica nanoparticles at $1400^{\circ} \mathrm{C}$.

Kay, J.P.; Nowok, J.W. Subtask 6.5 - SiAlON Coatings of Silicon Carbide and Silicon Nitride; Final Topical Report (May 1, 1999 - June 30, 2001) for U.S. Department of Energy Cooperative Agreement No. DE-FC26-98FT40320; EERC Publication 2001-EERC-06-05; Energy \& Environmental Research Center: Grand Forks, ND, June 2001.

\section{Subtask 6.6 - High-Temperature Materials}

Subtask 6.6 consolidated research on high-temperature materials in several areas representing new opportunities for developing technologies of importance to advanced power systems.

Silicon Carbide Particle Composites - Previous work under Subtask 6.3 developed reaction-bonded $\mathrm{SiC}$ joining materials for in-place joining of ceramic components. These joining materials exhibited good strength and no continuous channels of unreacted silicon, but the joints were porous and did not provide a strong bond at the interface with the pieces to be joined. This work was extended to include the use of the same reaction bonding materials to cast shapes that can be fired to produce ceramic components that require very little machining and are relatively inexpensive compared to pressure-sintered silicon carbide. Because there are no residual channels of unreacted silicon, this material will remain strong up to $1500^{\circ} \mathrm{C}$, unlike existing reaction-bonded $\mathrm{SiC}$, which begins to creep at temperatures above $1200^{\circ} \mathrm{C}$. Heated-stage $\mathrm{XRD}$ measurements indicated that slow heating to $1300^{\circ} \mathrm{C}$ followed by rapid heating at $500^{\circ} \mathrm{C} / \mathrm{min}$ to $1500^{\circ} \mathrm{C}$ under pressure allowed the reaction-bonding material to densify without leaving continuous Si channels. Although not as strong as dense $\mathrm{SiC}$, the material maintains the hardness of $\mathrm{SiC}$, and because of its microporosity, it can be impregnated with other materials such as polymers or metals to greatly increase the toughness and impact resistance of the structures at lower temperatures. Reaction-bonded $\mathrm{SiC}$ was investigated for fabricating "Whipple shields" 
that are used to protect spacecraft from meteoroid and debris impact. Under funding from the National Aeronautics and Space Administration (NASA), the EERC developed shields composed of a thin layer of SiC-resin composite bonded to sandwiched layers of aluminum honeycomb and woven carbon and Kevlar in epoxy. Tests on one composite performed at Rice University in Houston by personnel from the Johnson Space Center (JSC) using a gun firing $3.2-\mathrm{mm}$ aluminum beads at $4.2 \mathrm{~m} / \mathrm{s}(15,000 \mathrm{mph})$ showed that the projectile beads were vaporized as intended, but the layers of the sandwiched shield separated. Coupons of four different SiC-polymer composites were later supplied to Boeing for the Materials International Space Station Experiment 6 (MISSE-6) for shuttle launch in 2007. In addition, several SiC composite plates prepared with different polymers were supplied to the Sioux Manufacturing Corporation for testing as ballistic armor. All of the plates prevented penetration of 7.62-mm bullets, and most remained completely intact, whereas commercial SiC plates shattered.

Ceramic Nanoporous Membranes for Hydrogen Separation - Alumina-based multilayer membranes were prepared and tested for hydrogen separation from simulated coal gasifier syngas. The first membranes tested consisted of a macroporous disk, overlaid with a microporous layer and, finally, a nanoporous coating. At room temperature and a pressure of 60 psi, tests showed no increase in $\mathrm{H}_{2}$ but rather a $5 \%$ to $10 \%$ increase in $\mathrm{CO}_{2}$. At room temperature, the permeance of $\mathrm{CO}_{2}$ is more than twice that of $\mathrm{H}_{2}$, whereas it is less than half that of $\mathrm{H}_{2}$ at $250^{\circ} \mathrm{C}$. Tests at higher temperatures and pressures were subsequently performed on membranes prepared by coating a porous alumina tube sealed inside a stainless steel tube, which more closely models a membrane in a gasification system. No gas separation was observed in tests performed at pressures of 10 to $50 \mathrm{psi}$ and temperatures from ambient to $600^{\circ} \mathrm{C}$. SEM analysis indicated that the nanoporous coating layers were broken, cracked, and separated from the tubes. Better control of the shrinkage of the membrane coating and improved adhesion to the ceramic tube would be needed to successfully test this concept.

Refractory Corrosion under Controlled Atmospheres - A DSAF was constructed to test refractory materials with flowing slag in a controlled atmosphere. The bench-scale test facility consists of a $1600^{\circ} \mathrm{C}$ furnace, a slag granule feeder, and a castable alumina crucible to contain the sample and atmosphere. Mating surfaces were diamond-machined to ensure minimal gas leakage.

Use of Cenospheres in Corrosion-Resistant Low-Conductivity Refractory - Tests were performed in the DSAF to evaluate the addition of alumina-silica cenospheres produced during the combustion of coal to a corrosion-resistant castable refractory to decrease its density and thermal conductivity without substantially reducing its corrosion resistance. These aluminosilicate microspheres are 20-200 $\mu \mathrm{m}$ in diameter, have particle densities of $0.6-0.8 \mathrm{~g} / \mathrm{cm}^{3}$, high compressive strengths of 2000-5000 psi, are chemically inert, and melt at temperatures greater than $1600^{\circ} \mathrm{C}$. Test bricks made with a $98 \%$ alumina castable refractory, containing 5 and $10 \mathrm{wt} \%$ cenospheres, respectively, were fired to $1550^{\circ} \mathrm{C}$ in air. The $5 \mathrm{wt} \%$ cenosphere brick was tested in the DSAF under oxidizing conditions at 1400C for 25 hours with a slag from a commercial gasifier without showing measurable corrosion. The $10 \mathrm{wt} \%$ cenosphere brick was tested under more severe conditions at $1500^{\circ} \mathrm{C}$ for 50 hours with slag from Illinois No. 6 coal produced in the EERC SFS. Results were compared with a previous corrosion test run on the castable refractory without addition of cenospheres. Much greater corrosion was 
observed for the brick with $10 \mathrm{wt} \%$ cenospheres than for the one without. The increase in corrosion was believed to have resulted from porosity caused in part by the additional water required to make a castable mixture with the addition of cenospheres.

Hurley, J.P. Subtask 6.6 - High-Temperature Materials; Final Report (July 1, 2001 - Oct 31, 2007) for U.S. Department of Energy Cooperative Agreement No. DOE DE-FC2698FT40320; EERC Publication 2007-EERC-12-05; Energy \& Environmental Research Center: Grand Forks, ND, Dec 2007.

\section{Subtask 6.7 - Corrosion Studies of High-Temperature Alloys}

The corrosion rates of different superheater tube alloys under conditions representing a USC boiler were determined after 1000 hours' exposure to ash in a flue gas atmosphere at $625^{\circ} \mathrm{C}$. For conditions simulating the cofiring of bituminous coal with high-potassium biomass, alloys which formed an iron oxide scale experienced much greater corrosion than highchromium alloys that formed a chromium oxide layer. In tests on high-chromium alloys, the addition of water vapor did not significantly affect the oxide layer or the corrosion rate, but the addition of hydrochloric acid vapor resulted in some breakdown of the chromium oxide layer and an increase in corrosion. In tests representing the firing of high-sodium lignite, ODS alloys, which contain traces of inert metal oxides to stabilize the grain structure at high temperatures, experienced less corrosion than HCN alloys. Contrary to the expectation of greater corrosion for high-sodium lignite, little corrosion was observed for either type of alloy. Overall, ODS alloys offered the best corrosion protection. However, the HCN alloys, which provided only marginally less protection in these tests, should be evaluated further in reference to range of ash compositions and steam tube temperatures.

Hurley, J.P.; Strege, J.R. Subtask 6.7 - Corrosion Studies of High-Temperature Alloys; Final Report (Apr 1, 2003 - Dec 31, 2004) for U.S. Department of Energy Cooperative Agreement No. DE-FC26-98FT40320; EERC Publication 2005-EERC-06-06; Energy \& Environmental Research Center: Grand Forks, ND, June 2005.

\section{TASK 7.0 - STRATEGIC STUDIES}

Strategic studies were performed on emerging energy and environmental issues and related diagnostic methods and information transfer activities to provide technical and policy guidance for senior researchers and managers, either to support an existing EERC-NETL project or to develop new concepts for future research. Typical efforts conducted under this subtask were usually between $\$ 15,000$ and $\$ 60,000$ in scope and had time lines of less than 6 months. A limited number of larger studies were also conducted, generally at the direct request of NETL. Over the life of this subtask, 46 projects were conducted. The character of these efforts ranged from literature review, to limited experiments for testing a hypothesis, to research on the fundamental science supporting technology development, to a few larger engineering efforts. A separate Final Report on Subtask 7.1 has been submitted to NETL which includes a brief summary of each individual project. There is overlap between topics in Subtask 7.1 and four 
projects reported under Subtasks 7.2 and 7.3, all of which concerned climate change. Coverage here will be limited to strategic highlights from all of the research projects conducted.

\section{Projects Conducted under Subtask 7.1}

- Systems Engineering

- Climate Change Initiative

- Soil Flushing by Humic Acid Microemulsion

- Geographic Information Systems

- Alternative Sorbents for the Removal of Contaminants from Fluids

- Education Initiatives (Science in North Dakota and Educational Initiatives in Fossil Energy, Air Toxics, and Other Air Quality Issues)

- A Novel $\mathrm{CO}_{2}$ Photoreduction System via Sol-Gel Processing

- Industrial Relations

- Technology Adoption - Ceramic Materials Market

- Coalbed Methane

- Waste By-Products

- Emission Control Technologies

- Economic Evaluation of the Use of Manure-Based Reburn Fuels for the Reduction of $\mathrm{NO}_{\mathrm{x}}$ in Combustion Systems

- Photocatalytic Mercury Capture in Flue Gas

- Filter Blinding Reversal

- Hydrogen Membrane Testing

- Determination of Measureable Outcomes

- Waste Tire Recycling with Subcritical Water

- Feasibility of Using Freeze-Thaw Evaporation $\left(\mathrm{FTE}^{\circledR}\right)$ Technology for Power Plant Cooling Water Treatment 
- Effects of Fossil Fuel Power Plant Emissions on Precipitation

- Remediation Seminar

- Short Course - Ash Behavior and Mercury Control in Coal Combustion

- Review of Utility-Scale Energy Technologies

- Evaluation of ChemCAD Software

- Subcritical Water Fractionation of Particulate Matter

- Domestic Energy Parks

- Evaluation of Landfill Gas Applications

- Controlled Spontaneous Reactor

- $\mathrm{CO}_{2}$ Separation Technologies

- Mercury Measurement in Combustion Flue Gases Short Course

- Installation of an Additional Wet Scrubber on the EERC's 7-kW Combustion System

- Microbial Cycling of $\mathrm{CH}_{4}, \mathrm{CO}_{2}$, and $\mathrm{N}_{2} \mathrm{O}$ in Wetland Environments - A Scoping Study

- Residential Energy Issues

- Hydrogen Storage Material

- Materials Testing

- Oil Field Applications for Low-Btu Associated Gas

- Development of a Novel Petroleum Biotechnology

- Potential for Conversion of Beet Sugar

- Biomass Product Separation and Characterization for the Generation of Fuel Additives

- Analysis of Oil and Gas Environmental Issues Affecting Domestic Production

- Student Involvement Activities

- Filter Cake Properties 
- High-Temperature Corrosion of Alloys in Simulated Boiler Tube Conditions

- On-Demand High-Pressure Hydrogen Extraction and Dispensing for Vehicle Fueling

- Indirectly Fired Combined Cycle with Condensing Heat Exchanger

- Engineering Opportunities and Challenges of $\mathrm{CO}_{2}$ Mitigation Using Microalgae in Fossil Fuel-Fired Power Plants

Erickson, T.E. Subtask 7.1 - Strategic Studies; Final Report (Apr 1, 2005 - Mar 31, 2009) for U.S. Department of Energy Cooperative Agreement No. DE-FC26-98FT40320; EERC Publication 2009-EERC-06-01; Energy \& Environmental Research Center: Grand Forks, ND, June 2009.

\section{Projects Reported under Subtasks 7.2 and 7.3}

- Quantifying Global Climate Change

- Mitigating Greenhouse Gases

- Global Warming and Greenhouse Gases

- Socioeconomic Impacts of Climate Shifts in Northern Great Plains

Aulich, T.R.; Timpe, R.C. Subtask 7.2 - Economic Source-Sited Long-Term $\mathrm{CO}_{2}$ Sequestration; Final Report (Apr 1, 2001 - June 30, 2002) for U.S. Department of Energy Cooperative Agreement No. DE-FC26-98FT40320; EERC Publication 2005-EERC-01-05; Energy \& Environmental Research Center: Grand Forks, ND, January 2005.

Buckley, T.D.; Simonsen, T.; Solc, J. Subtask 7.3 - The Socioeconomic Impact of Climate Shifts in the Northern Great Plains; Final Report for U.S. Department of Energy Cooperative Agreement No. DE-FC26-98FT40320; EERC Publication 2008-EERC-01-01; Energy \& Environmental Research Center: Grand Forks, ND, January 2008.

\section{Selected Highlights of Strategic Studies}

Climate Change - Trends in measurements of atmospheric $\mathrm{CO}_{2}$ and global temperatures in this century point to anthropogenic impacts related to industrial and agricultural practices which must be interpreted in the context of natural changes in climate in order to gauge their ultimate extent and impact and to plan mitigation efforts. A key element in any study of climate change is an understanding of the pattern of short-term cycles. To provide a basis for understanding natural climate variability in the late Holocene (i.e., the last 5000 years), seventy papers covering a wide range of climate interests were examined. Information in selected categories was carefully coded and input into a database to facilitate the sorting of the data according to area, time coverage, methodology, or other field of interest. By placing these data sets and methods in a position to be evaluated on the same bases, conclusions can be more appropriately synthesized and compared. In a companion activity, climate trends in north-central North Dakota over the past 2000 years were reconstructed based on the paleohydrologic history of Devils Lake, which has no temporally continuous outlet and registers large changes in water 
level and salinity in response to changes in precipitation. Analysis of sediment profiles from the lake bottom identified a pattern of 150-year wet-dry cycles which need to be taken into account in planning mitigation of impacts on regional availability of water for energy and agriculture associated with both natural and greenhouse-gas related climate change.

$\mathbf{C O}_{2}$ Capture - Processes for separating $\mathrm{CO}_{2}$ from other gases were reviewed in advance of the EERC's Plains $\mathrm{CO}_{2}$ Reduction (PCOR) Partnership under the Regional Carbon Sequestration Partnership Program. Commercial-scale processes have been in use for over 50 years to remove $\mathrm{H}_{2} \mathrm{~S}$ and $\mathrm{CO}_{2}$ from natural gas and to purify syngas to produce hydrogen for oil refineries or ammonia production. Enhanced oil recovery (EOR) provides an important economic incentive for expanding the production of $\mathrm{CO}_{2}$, including the capture of $\mathrm{CO}_{2}$ from power plants. In exploring new methods for capturing $\mathrm{CO}_{2}$, Group VIII transition metal oxotitanates containing $\mathrm{Co}, \mathrm{Ni}$, and $\mathrm{Ru}$ were synthesized and characterized by IR spectroscopy to measure their reactivity for photoreduction with visible light. Also, the use of microalgae to capture $\mathrm{CO}_{2}$ from coal-fired power plants was evaluated based on the status of industrial microalgae culturing in open ponds and closed photobioreactors and in reference to the inhibiting effects of acid gases in flue gas on algal growth that would have to be addressed if stack gases were to be used directly. Literature was surveyed to identify opportunities for microbially mediated biogeochemical cycling of $\mathrm{CH}_{4}, \mathrm{CO}_{2}$, and $\mathrm{N}_{2} \mathrm{O}$ in the glaciated North American prairie, which previously supported the largest wetland complex in North America but has been converted to agriculture to become a net source of atmospheric $\mathrm{CO}_{2}$.

Water - Studies were performed to understand the impacts of fossil fuel production and utilization on water supply and quality in the context of basinwide water management practices. Additional work was directed toward recovery and reuse of water from oil and gas production and from power plant stack gas. Future exploration and production of CBM in the Montana portion of the PRB was put on hold by state regulators pending an environmental impact statement (EIS) addressing the impacts of removing large volumes of water from aquifers, which is required to lower the water pressure that confines the methane within the coal seams. Water is becoming scarce and expensive in many parts of the western United States, especially in California where there is already a strong economic incentive to reduce the net cooling water requirements of power plants. Calculations were performed to determine the amounts of water that could be recovered from flue gases generated from the combustion of different fuels under varying conditions of temperature, combustion mode (air versus oxygen combustion), use of a condensing heat exchanger, and use of a desiccant system. The potential amount of water that could be recovered from flue gas is sufficient to significantly reduce and, in some cases with air or hybrid air-water cooling, eliminate the need for off-plant sources of water. In addition, condensing water from flue gas may provide opportunities for removing $\mathrm{SO}_{2}$ and $\mathrm{NO}_{\mathrm{x}}$ to lower levels to approach near-zero emissions of acid gases. Further integration with oxygen-blown combustion would both enhance water recovery by increasing the partial pressure of water in flue gas and provide a clean source of $\mathrm{CO}_{2}$ that could be used for tertiary oil recovery or sequestration. In addition, integration of the EERC's FTE ${ }^{\circledR}$ technology into power plant cooling water would recover water from cooling tower blowdown and concentrate brine for disposal, and additional power generation would be realized as a result of enhanced cooling during seasonal periods of ice melt. 
Hydrogen - Scoping studies were performed on the production, separation, and storage of hydrogen in planning a focused program at the EERC. A key barrier to commercialization of fuel cell-powered vehicles is the lack of a viable hydrogen fueling infrastructure. Automakers and oil companies are developing technologies for on-board vehicle extraction of hydrogen from gasoline and methanol, but all generally agree that this is a near-term approach to be utilized only until the advent of economical hydrogen fueling via dispensers that are similar in safety and ease of operation to today's gasoline pumps. Plans were developed for a small extractionpurification-dispensing system that would deliver high-pressure hydrogen on demand by reacting natural gas (which is easier, safer, and cheaper to compress than hydrogen) with water in a high-pressure chamber for direct refueling of a vehicle. Sufficient information was obtained to move toward development with an industrial partner.

Systems Engineering - The EERC's capabilities for evaluating the technical potential and economic feasibility of new energy systems were advanced by developing and acquiring software and by training researchers in its application. A series of Lotus and Excel spreadsheet programs were developed to recursively calculate energy, mass, and elemental balances for gasification and combustion systems. State-of-the art software was acquired for chemical process simulation and computational fluid dynamics (CFD) modeling, including ChemCAD, ASPEN, and the FLUENT CFD model. The EERC's GIS's were enhanced by acquiring software upgrades and a scanner for directly incorporating data from hard copies of maps and by interfacing with global positioning system (GPS) equipment. Selected applications from among the many that used systems engineering capabilities include CFD with cold-flow modeling and recursive spreadsheet models to evaluate the design and operating performance of the EERC's TRDU transport gasifier in reference to the effects of flow, mixing (residence time distribution), and reaction kinetics for multiple recycle passes - and also to predict performance in reference to fuel properties that had not been experimentally investigated, including high levels of moisture and ash contents. A recursive spreadsheet incorporating data on vapor-liquid equilibria for desiccant solutions was used to calculate the potential for recovering water from power plant stack gas along with estimates of boiler efficiency and electric generating efficiency as a function of fuel properties and plant operating conditions such as stack temperature, steam temperature and pressure, reheat cycles, and cooling water temperature. ASPEN and recursive spreadsheets were used to evaluate operating conditions for oxycombustion, including the amount of flue gas recycle required to limit combustion temperature for particular fuels, to guide in the preparation of design modifications for operating the EERC's $100-\mathrm{lb} / \mathrm{hr}$ pc-fired combustion system on oxygen. An analysis was performed on the economics of integrating large-scale wind power development with fossil fueled plants as an option for significantly reducing carbon dioxide emissions. Enhancement of systems engineering is a continuing goal of the EERC.

\section{Subtask 7.4 - Powder River Basin Subbituminous Coal-Biomass Cogasification Testing in a Transport Reactor}

In this subtask, $20 \mathrm{wt} \%$ of biomass was mixed with a previously tested baseline PRB subbituminous coal from the Peabody Energy North Antelope Rochelle Mine near Gillette, Wyoming and tested in the EERC's TRDU. Two types of biomass were tested: wood waste and switchgrass. The goal was to compare operating data and sample chemistry for the coal-biomass test with previous results for the PRB coal alone. Gas and particulate sampling at several 
locations in the gasifier riser provided information on coal devolatilization and cracking chemistry as a function of residence time, transport gas, and mode of operation. Data were provided to the U.S. Department of Energy (DOE) to determine kinetics of devolatilization and tar cracking. The focus of the tests performed in oxygen-blown mode was on FT coal-to-liquid production. Since coal liquids have a larger carbon footprint than liquid fuels from petroleum, a successful demonstration cofeeding biomass has the advantage of reducing the net carbon emission of FT liquids from the syngas.

In past tests, over 3600 hours of operation has been competed on 17 different coals ranging from bituminous to lignite and on petroleum coke. The extensive database on these fuels, variously operating in either air- or oxygen-blown modes, provides a useful basis for estimating the effect of feedstock properties and for making design changes. Corrected fuel gas heating values on a dry basis have typically ranged from 90 to $130 \mathrm{Btu} / \mathrm{scf}$ in air-blown mode and up to $230 \mathrm{Btu} / \mathrm{scf}$ in oxygen-blown mode. The factors that have the greatest effect on product gas quality are coal type, temperature, and oxygen/fuel ratios. Carbon conversions are highly dependent on the oxygen-coal ratio, but can exceed $90 \%$. Highly reactive LRCs perform better than the less reactive bituminous coals.

In this test series, both wood waste and switchgrass were successfully fed and gasified at a $20 \mathrm{wt} \%$ blend ratio. Results indicated a very high carbon conversion, good syngas heating value, and no bed agglomeration or other operating problems. Preliminary tests at 25 to $30 \mathrm{wt} \%$ biomass indicated that fuel feeding at these higher percentages would be more problematic. Gas and solid samples from five locations in the reactor indicated very little coal backmixing in the mixing zone. With increasing residence time, the concentration of aliphatics present in the gas decreased, while the concentration of aromatics increased slightly. Higher gasifier temperatures resulted in lower methane and aliphatics concentrations and higher aromatics concentrations. Significantly higher levels of organic compounds were observed in the lower regions of the riser when biomass was fed, with its high volatile matter content. However, for the product gas exiting the reactor, the organic concentrations were very similar for tests on coal alone and tests on the biomass-coal blend.

Laudal, D.; Swanson, M.L. Subtask 7.4 - Powder River Basin Subbituminous Coal-Biomass Cogasification Testing in a Transport Reactor; Final Report (Aug 1, 2007 - Mar 31, 2009) for U.S. Department of Energy Cooperative Agreement No. DE-FC26-98FT40320; EERC Publication 2009-EERC-05-10; Energy \& Environmental Research Center: Grand Forks, ND, May 2009. 